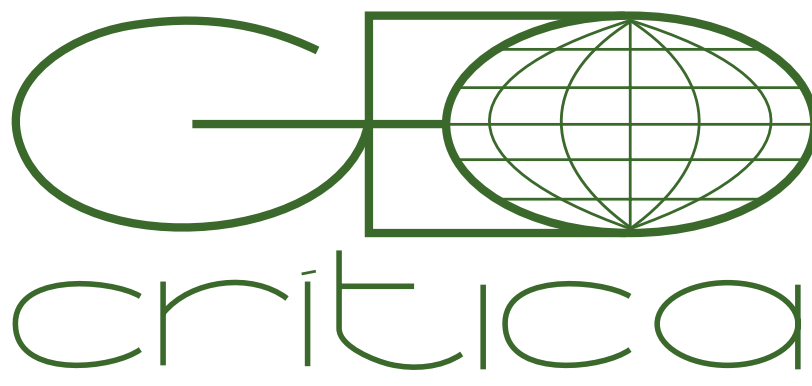

\section{Scripta Nova}

Revista Electrónica de Geografía y Ciencias Sociales Universitat de Barcelona

1 de Mayo de 2020

\title{
GENERACIÓN 19S. CARTOGRAFÍA AFECTIVA DEL SISMO DEL 19 DE SEPTIEMBRE 2017 EN MÉXICO
}

\author{
Julie Boudreau \\ boudreau@igg.unam.mx \\ Carlos Castro Reséndiz \\ castrocar@gmail.com \\ Evelyn Mejía López \\ mjlp.vlyn@gmail.com \\ Tonalli Romero \\ tonaliromoreno@gmail.com
}

Universidad Nacional Autónoma de México

Queremos agradecer a los 45 jóvenes quien compartieron su experiencia en este proyecto de investigación, así como el Programa Universitario de Estudios de la Ciudad de la Universidad Nacional Autónoma de México (PUEC-UNAM) por su apoyo. En particular al Dr. Javier Delgado, director del PUEC por su entusiasmo en este proyecto, $y$ al equipo de difusión y comunicación del PUEC por su apoyo en el registro de los talleres y la edición de los videos disponibles en la plataforma web diseñada por Aldo Magaña.
Recibido: 25 enero 2019; Devuelto para correcciones: 26 marzo 2019; Aceptado: 19 septiembre 2019

\section{Generación 19s. Cartografía afectiva del sismo del 19 de septiembre 2017 en México (Resumen)}

A través de un proceso de cartografía narrativa y participativa se registra la memoria de las acciones de jóvenes brigadistas posteriores al sismo del 19 de septiembre de 2017 en México. Se realiza un análisis de la construcción subjetiva de los jóvenes, un análisis comparativo con la generación anterior que vivió el sismo de 1985, y también una primera aproximación del impacto socio político derivado de la participación de la población civil. Se sugiere que la acción voluntaria tras el terremoto ha permitido reconstruir simbólicamente la ciudad porque la acción de los jóvenes en lugares específicos ha producido nuevos lugares emocionales, así como sujetos políticos. Construir lugares significa construir la ciudad, una forma prefigurativa y emergente de acción política en un mundo donde la cultura urbana es dominante.

Palabras claves: lugares afectivos; cartografía narrativa; sismo; acción política; México

\section{9s generation. Affective mapping of the earthquake of September 19 of 2017 in Mexico (bstract)}

Through narrative and participative cartography, we analyse young volunteers' memory in the wake of the September 19, 2017 earthquake in Mexico. We analyze youth subjective construction comparatively with the previous generation who lived the 1985 earthquake. We further develop a first approximation of the socio-political impact derived from this volunteer work. It is suggested that voluntary action after the earthquake has allowed the symbolic reconstruction of the city because young people's action in specific places has produced new emotional places, as well as political subjects. Building places means building the city, a prefigurative and emerging form of political action in a world where urban culture is dominant.

Keywords: affective places; narrative mapping earthquake; political action; Mexico City 
El 19 de septiembre de 2017 se conmemoraba un año más del sismo de 1985 en la Ciudad de México. Datos oficiales ${ }^{1}$ hablan de los efectos negativos para la ciudad, la ciudadanía y el país de entre 10 mil a 20 mil muertos, perdidas económicas del alrededor del 2.4\% del Producto Interno Bruto, así como el derrumbe de alrededor de 2800 edificios. Justo a las 13:14 horas del 19 de septiembre, pero 32 años después otro fenómeno sísmico con epicentro a unos cientos de kilómetros (en el vecino estado de Puebla) de la Ciudad de México tuvo efectos devastadores, dejando en los primeros reportes un total de 369 víctimas mortales, miles de damnificados y daños materiales en edificios y vienes inmuebles.

Aun y cuando los impactos en términos materiales y de muertes relacionadas con los efectos del sismo de 2017 con relación al de 1985 fueron menores, lo que fue notorio es el apoyo y las manifestaciones de ayuda por parte de todos los sectores de la sociedad. Pero, así como hace 32 años y al igual que en esa época fueron los jóvenes quienes demostraron su valor.

El proyecto Generac19n, surge de la observación de la acción visible e intensa de las juventudes a partir de los efectos del sismo del 19 de septiembre 2017 en la Ciudad de México. ${ }^{2}$ El concepto Generac19n buscaba identificar los cambios para construir una ciudad nueva a través de pequeñas y grandes acciones, así como la experiencia de aquellos que vivieron y apoyaron con su labor a reconstruir la ciudad, este proyecto nos ayudó a identificar el futuro que se está construyendo por parte de la ciudadanía. Nos propusimos entonces hablar de la Generac19n, en referencia a la fecha del temblor.

GEN - gente, género

ERA - historia, memoria

C19N - Ción de movimiento, acciones en lugares específicos

(http://generacion19s.puec.unam.mx/)

Antes del sismo, esta generación de jóvenes era vista por los medios de comunicación y algunos sectores de la sociedad como una generación apática, con escaso interés en la participación política. A partir del sismo del 19 de septiembre 2017, las juventudes tomaron un papel visiblemente activo. ${ }^{3}$ El no haber experimentado un sismo de esa magnitud a diferencia de quienes vivieron el sismo de 1985 supuso un

1 El centro de Instrumentación y registro sísmico: http://www.cires.org.mx/1985_es.php Portal BBC: https://www.bbc.com/mundo/noticias/2015/09/150917_mexico_sismo_antes_despues_fotos_an El Financiero: https://www.elfinanciero.com.mx/sismo-1985/terremoto-destruyo-del-pib-del-pais Excélsior: https://www.excelsior.com.mx/comunidad/2015/09/17/1046211

2 En 2017 se registraron más de veinte seis mil movimientos telúricos en todo el país, de los cuales 102 superaron los cinco grados Richter. Dos sismos fueron los que dejaron la mayor cantidad de víctimas y pérdidas materiales. El primero ocurrió el día 7 de septiembre, en el municipio de Juchitán en el Estado de Oaxaca con una intensidad de 8.2 grados Richter y el segundo el día 19 del mismo mes, con epicentro en el en el municipio de Axochiapán, localizado en el límite del estado de Morelos y Puebla, con una intensidad de 7.1 grados Richter.

3 Preferimos hablar de juventudes en plural, pues nos ayuda a enfatizar la diversidad como una forma política y un estilo de vida, en lugar de la juventud como una categoría que esencializa y homogeniza las distintas expresiones socioculturales de ser jóvenes. 
cambio en la forma en que viven la ciudad y cómo se modificó a partir de la magnitud de un evento socio-ambiental, por ello la lectura de su papel en la sociedad cambió; nos interesa visibilizar su papel en las horas posteriores al sismo y en la reconstrucción de la ciudad. A veces, un evento es tan importante que marca una generación.

Un acercamiento a la reciente literatura científica producida desde las ciencias sociales sobre los efectos de los terremotos en América Latina actualmente se muestra que la mayor parte de los trabajos se centran en las desigualdades sociales, económicas y de género en situaciones de emergencia. Algunos autores lo han llamado el "desastre social"4, otros autores destacan la condición de crisis permanente del Estado, que en el caso particular mexicano es la crisis de la representación política, de la participación política y de la seguridad pública. ${ }^{5}$ Todos estos puntos de vista que fueron compartidos por la mayoría de los participantes durante la investigación, pues más allá de su optimismo y su entusiasmo por los esfuerzos de cooperación, la mayoría de los jóvenes fueron críticos ante la nula respuesta del gobierno, la corrupción relacionada a la laxitud en los permisos de construcción y a la deficiente calidad en la construcción de los edificios por parte de las inmobiliarias.

Por el contrario, si observamos el análisis que se realizó tras el terremoto de 1985 en la Ciudad de México, el tono es mucho más optimista, y se centra en el papel de la sociedad civil, la construcción de ciudadanía y el fortalecimiento de la incipiente democracia mexicana. Por ejemplo, se destaca el desastre que significó el Estado mexicano para resolver la urgencia y los efectos sociales del terremoto, y como esto significó un estímulo para las juventudes y su participación en el proceso de democratización, la institucionalización de los principios de la justicia espacial en los programas de desarrollo urbano y los inicios de una cultura de la protección civil. Pero lo más importante en estas investigaciones es el análisis de las nuevas formas de organización de la sociedad civil, la organización popular y el surgimiento de un nuevo sujeto social ${ }^{6}$. Una manera de resumir estas diferencias generacionales es: ${ }^{7}$ :

En términos generales, hubo diferencias en la respuesta de la población, así como en su vinculación con el aparato gubernamental. En 1985 se evidenció el autoritarismo que imperaba en una entidad federativa que no tenía derecho a elegir a sus representantes. En cambio, en 2017, el sismo fue otra muestra más de la separación entre los habitantes de la ciudad y sus gobernantes; con un gobierno que se dice de izquierda, elegido mediante votación, pero igualmente ineficiente para dar una pronta respuesta ante la crisis.

Un punto de similitud fue que, tanto en 1985 como en 2017, los medios de comunicación y los académicos hablaron ampliamente sobre la importante participación de las juventudes y la sociedad civil después de los terremotos ${ }^{8}$. Sí partimos del hecho de que el contexto económico y político de 2017 y 1985 es distinto, nos

4 Velázquez, 2018.

5 González, 2018; Aguiar, 2017.

6 Street 1991; Monsiváis 1987; Ortega 1987; Schteingart, Martha y Lezama 1986.

7 López y Valverde, 2018, p. 29

8 Castillo, 2018 
preguntamos ¿Qué hizo posible que el trabajo de la sociedad civil en 1985 tuviera un mayor optimismo en términos del fortalecimiento de la ciudadanía contrario al del 2017? ${ }^{9}$ Tal vez nuestra perspectiva histórica está muy cercana con lo ocurrido durante el sismo del 2017, como para analizar adecuadamente los impactos sociopolíticos y la construcción de una nueva forma de hacer ciudad. Por ello, lo que analizamos son categorías vivenciales como las emociones, motivos y sentimientos y su relación con la movilización de la sociedad civil que hablen de su experiencia urbana.

Para responder a esa pregunta, el presente texto inicia con una breve discusión epistemológica sobre la importancia de la cartografía desde la geografía afectiva. En un segundo apartado, presentamos la metodología de la investigación; en particular el uso de la cartografía narrativa y crítica y el proceso que se llevo a cabo para recolección de los datos. En el siguiente apartado, ofrecemos un "tour" de los lugares que tuvieron mayor carga afectiva después del sismo del 19S 2017 en México. El texto concluye con una discusión teórica-metodológica de la perspectiva afectiva de la acción sociopolítica desarrollada con base en los datos de cartografía narrativa.

\section{Acercamientos teóricos: ¿Cuál es el mapa de México producido por los jóvenes urbanos en los días posteriores al sismo del 19S?}

Mientras el mundo adulto avanzaba a tientas y mirando el espejo retrovisor para tratar de resolver el presente, los jóvenes estaban construyendo potentes herramientas de recolección, captura y difusión de datos, filtros críticos en tiempo real para tener la información más fidedigna sobre lo que ocurría, y alianzas afectivas altamente políticas por su capacidad de mostrar posibilidades de organización social sin jerarquías ni burocracias institucionales. ${ }^{10}$

No solamente los jóvenes en el 2017 "estaban construyendo potentes herramientas" sino también, como lo veremos más adelante, (re)construyeron la ciudad en términos simbólicos, pero sobre todo su experiencia urbana. Lo anterior es relevante, pues en un mundo en donde la cultura urbana es hegemónica, la acción política se desarrolla de manera diferente, ya no estamos en un mundo de estados-nación como fue el caso del terremoto en 1985 caso contrario al del 2017 pues en un mundo urbano, la política ya no es vista como un dominio exclusivo del Estado, la escala de intervención se acorta y da posibilidad de actuar en lo local. La acción se desarrolla en espacios en red, fluidos y móviles que no están fijados por fronteras claras. Lo anterior conlleva a una ontología relacional y el reconocimiento de la materialidad y el cuerpo como escalas espaciales y de intervención, a su vez eso ha

9 Allier Montaño (2018:15) trata de trazar algunas claves, así compara la cobertura mediática de los terremotos de 1985 y 2017, e indica cómo "tanto Monsiváis como Poniatowska ... dieron esa lectura inicial (que se ha ido transformando en hegemónica) del terremoto de 1985 como el "surgimiento de la sociedad civil." Así, Allier Montaño concluye sobre el sismo de 2017, "Y aunque se despertó una importante movilización social, no parece que se esté generando el mismo impacto que en 1985". (op cit, p. 36).

10 Abrego,2018, p. 199 
"permitido abordar los mundos afectivos más allá de marcos normativos al repensar las categorías de espacio y tiempo." ${ }^{11}$

Aunque México es un país predominantemente urbano desde los años 1970 (en términos demográficos), es con el inicio del siglo XXI que la cultura urbana se ha globalizado hasta devenir una ontología dominante. ${ }^{12}$ La urbanidad así afecta a nuestras concepciones del espacio, el tiempo y la racionalidad. ${ }^{13}$ Dónde, cuándo y cómo se desarrolla lo político y la democracia ya no es exclusivamente en la cabina de votación o en la reunión sindical, durante las elecciones o las huelgas, a través del pensamiento estratégico para ganar la competencia entre intereses opuestos. A medida que las instituciones estatales pierden su monopolio sobre la gobernabilidad, es decir, sobre la distribución de la justicia y la autoridad, los modos de vida urbanos están poniendo de relieve nuevas formas políticas, lo cual estaba sucediendo en el 2017 y sigue en proceso hoy día.

Lo anterior, tiene consecuencias importantes para la forma en que se producen la cartografía y los mapas. Por ejemplo, la lógica de la representación enciclopédi$\mathrm{ca}^{14}$ que dominó los siglos pasados ya no puede mantenerse en el mundo urbano contemporáneo. La lógica moderna de la representación funciona depositando el significado experiencial en las instituciones. Pero el mundo urbano muestra ahora claramente que estas instituciones no han evolucionado tras los cambios sociales: son anticuadas y excesivamente especializadas.

Regresar a la experiencia es un imperativo histórico. Hay que volver a construir sentido político tomando la calle, hay que volver a construir sentido estético desplegando nuestras habilidades imaginativas, desplegando nuestros saberes, volviendo a reconstruir la propia experiencia estética y hay que volver a ser cartógrafos para refundar el sentido de cuál es el valor del espacio, como podríamos estar en él, como podríamos discurrir con él. ${ }^{15}$

En términos cartográficos, esto significa partir de la experiencia y no de la funcionalidad para describir el mundo: "Un mapa que ya no representa el territorio, sino que da cuenta de que el territorio ha de ser un espacio disponible para transcribir un renovado mundo de experiencias." ${ }^{16}$ Por ello, la cartografía afectiva "registra en el espacio y tiempo una ciudad latente, expresión de la pasión impresa temporalmente en la ciudad por las acciones de sus ciudadanos." ${ }^{17}$ Por ejemplo, entre 1957 y 1972, los Situacionistas exploraron varias técnicas cartográficas dentro de lo que llamaron la psicogeografía, buscando sentir la ciudad y mapearla desde el sujeto.

11 Depetris y Taccetta, 2017, p. 359

12 Burdett y Sudjic, 2010

13 La urbanidad, o formas de vida urbanas, se refiere a un conjunto de condiciones históricas que afectan la forma en que actuamos, interactuamos y pensamos sobre el mundo. En otras palabras, a medida que las ciudades se hacen más prominentes en nuestras concepciones del mundo, la manera en que concebimos el espacio, el tiempo y la racionalidad de la política está cambiando (Boudreau, 2017).

14 Perán, 2013, p. 109

15 Perán, Op cit.

16 Ibid, p. 110

17 Sansao-Fontes y Till, 2017, p. 248 
Así el llamado "giro afectivo" en las ciencias sociales desde los noventas se inspira mucho del trabajo de este movimiento intelectual-artístico-activista.

En el presente trabajo, nuestro objetivo es entender el proceso de construcción subjetiva de los jóvenes, a través del apoyo que realizaron después del sismo del 19 de septiembre 2017. ¿Cuál es el mapa emocional de México producido por los jóvenes urbanos en los días posteriores al sismo del 19S? Pocos trabajos analizan los sismos urbanos y se focalizan en esa perspectiva subjetiva y experiencial. En el caso de la Ciudad de México, algunos proyectos artísticos presentan una recolección de testimonios (Secretaria de Cultura de la CDMX, 2018). En el ámbito académico, algunas autoras proponen el concepto de "cuerpos/emociones intermediarios"18, es decir que en situaciones de emergencia, "encontramos habilidades exaltadas de sociedades y sujetos, que logran superar sus marcos de actuación al identificar, percibir, entender señales emergentes en contextos de alerta extrema que intensifican y aumentan los sentidos que han tenido interacciones sociales conocidas, que las abandonan superando tensiones dadas por la estructura y dominación social."

La mayoría de los testimonios que recolectamos hablan de esa temporalidad vinculada a la emergencia, de estas emociones intensas y de la enorme energía individual y colectiva que se dio durante el trabajo que realizaron. Sin embargo, la perspectiva de los cuerpos/emociones no permite ver más allá de la emergencia. Así nuestro interés es entender los efectos de esas experiencias en la ciudad, la sociedad y explorar la articulación entre los sujetos, las emociones, el lugar específico y la acción no solamente inmediatamente después del sismo, pero también con temporalidades más largas.

Esto es lo que llamamos lugares afectivos, para ello nos basamos en la geografía afectiva. Los afectos circulan y se transforman a sí mismos a medida que transforman los cuerpos en situaciones de acción específicas. ${ }^{19}$ Estos tiempos y espacios fugaces, donde el afecto recorre nuestros cuerpos antes de que seamos conscientes de ello, son de hecho altamente políticos, pues representan la primera escala espacial, es cuerpo como un lugar y el cuerpo al no estar desvinculado de las emociones y la experiencia urbana denota espacialidad.

Muchos lugares afectivos son el resultado de nuevas tecnologías y conocimientos desarrollados a través de la psicología y el marketing, así como del diseño urbano. La producción cada vez más elaborada de ambientes urbanos, a través de la iluminación o la producción de eventos, apela al razonamiento afectivo más que al cognitivo ${ }^{20}$. Los efectos excluyentes de quienes pueden estar libremente en esos entornos urbanos han sido criticados por muchos. Las racionalidades afectivas son realmente poderosas y, por lo tanto, altamente políticas y espaciales.

Sin embargo, con su labor de apoyo, la generación 19S construyó otros tipos de lugares afectivos ${ }^{21}$. Los jóvenes que salieron a apoyar después del sismo recons-

18 Camarena y Salgado, 2018, p. 42

19 Ortiz Guitart, 2012; Abramowski y Canevaro, 2017

20 Thrift, 2004

21 Utilizamos la definición de lugar de Escobar y Pedroza (1996) como la ubicación de una 
truyeron lugares, tanto en sus significados y afectos como en su aspecto estético. Los lugares producen sujetos, potencia e invención. Algunos autores ${ }^{22}$ explican que “insertar acciones temporales y tácticas en el mapa significa reconocer esas nuevas dinámicas, relacionarlas a los lugares por los cuales las personas tienen afecto, se apropian y reconquistan, y hacerlas menos efímeras, mas "permanentes", permitiendo el reconocimiento de esa capa urbana latente." En otras palabras, los lugares son una forma emergente y constructiva de la acción política. Se tienen que analizar a través de múltiples temporalidades ${ }^{23}$. Primero, el lugar produce lugareños, es decir sujetos quien constituye el lugar, sus afectos, su estética. Segundo, el lugar tiene un ritmo corporal, es decir toma vida en lo cotidiano (quehaceres). Finalmente, un lugar tiene una historia, se reproduce en la memoria. El mapa afectivo juega un papel clave en la circulación de la memoria. Como lo explicó Marco uno de los participantes, al principio (del apoyo) "era una especie de anarquí funcional, va aflorando la organización no conforme a un plan, sino conforme a la necesidad que lo va exigiendo."

Así, analizamos los lugares más significativos de la Ciudad de México y los estados de alrededor tras el sismo del 19 de septiembre 2017. Por ejemplo, para los participantes el salir a apoyar los situó y produjo como sujetos de acción (el lugar produce lugareños). A medida que su labor de apoyo se organizó de la espontaneidad en los minutos después del sismo a la formación de micro-organizaciones en lugares específicos, identificamos cómo estos nuevos lugares se estabilizaron (el lugar tiene un ritmo cotidiano) y finalmente, estos lugares quedan en la memoria urbana de los jóvenes que los reconstruyeron, y en la memoria colectiva de los habitantes como la historia del sismo.

\section{Metodología de la investigación}

Con el objetivo de recopilar y analizar la memoria, emociones, motivos y experiencia de las 45 personas ${ }^{24}$ que participaron con esfuerzo civil y colectivo en los minutos, días, semanas y meses después del sismo, desarrollamos una metodología participativa mediante la cartografía narrativa. Los mapas narrativos y afectivos buscan representar de manera visualmente eficaz una colección de historias, cronología y distintas escalas espaciales, usando varios tipos de datos a nivel de textos, fotografías, dibujos, videos y/o audios de personas que narran una experiencia.

Para el caso del Proyecto Generacl9Sn, se trabajó con jóvenes de entre 18 a 35 años que apoyaron de alguna manera durante el sismo del 19 de septiembre de 2017. Para ello lo relevante fue identificar de manera espacial, las emociones, el tipo

multiplicidad de formas de política cultural, es decir de conflicto entre actores que buscan otorgar nuevos significados a las interpretaciones culturales dominantes.

22 Sansao-Fontes y Till, 2017, p. 248

23 Vergara, 2015

24 En total, organizamos siete talleres entre el 8 de noviembre 2017 y el 27 de enero 2018, que duraron entre dos y tres horas, con 45 participantes. Los talleres se hicieron en el Instituto de Geografía de la UNAM, el Programa Universitario de Estudios de la Ciudad de la UNAM, y en la Casa de la Cultura "Profr. Jesús Romero Flores", en la colonia Condesa. La muestra fue teórica en términos de género, edad y alcaldía de procedencia, así como su perfil de estudiantes. 
de apoyo y las motivaciones que estaban presentes durante el apoyo que dieron a los damnificados en la Ciudad de México, el Estado de Morelos, y el Estado de México, principalmente. El trabajo se realizó en tres etapas. La primera, consistió en un grupo focal para conocer los recorridos espaciales que realizaron los participantes para brindar su apoyo, así como discutir entre ellos sobre el tipo de apoyo que otorgaron: psicológico, médico, quitando escombros, dando de comer, evaluando inmuebles, recopilando información, llevando víveres o hasta realizando actividades de entretenimiento (Figura 1).

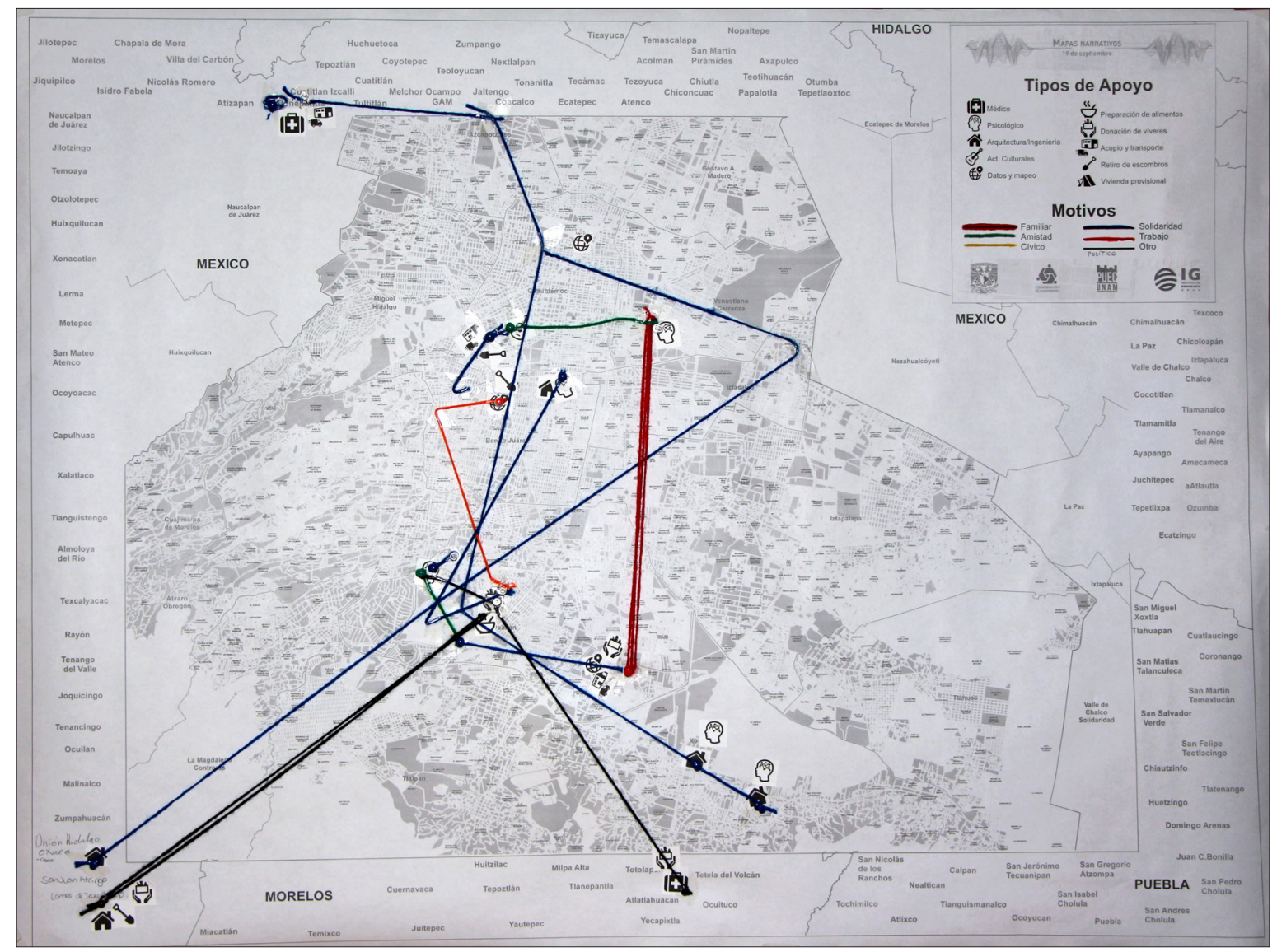

Figura 1: Mapa participativo para identificar los tipos de apoyo, motivos y la extensión geográfica del apoyo en la Zona metropolitana de la Ciudad de México.

Fuente: Elaboración propia a partir de los datos del grupo focal (22 de noviembre 2017)

La segunda, consistió en que contaran las emociones vinculadas a una experiencia que sucedió en algún lugar en el cual brindaron su apoyo (Figura 2). Nos interesa vincular las emociones con el lugar y cómo los marcó esta experiencia personal. Por último, hacia el final de las sesiones, se discutió con los participantes sobre: ¿Cómo fue la relación con otras generaciones? ¿Qué pensaban del actuar del Gobierno? Finalmente, ¿Cuáles eran las diferencias entre ellos y la generación que ayudó durante el sismo de 1985 en la Ciudad de México? 


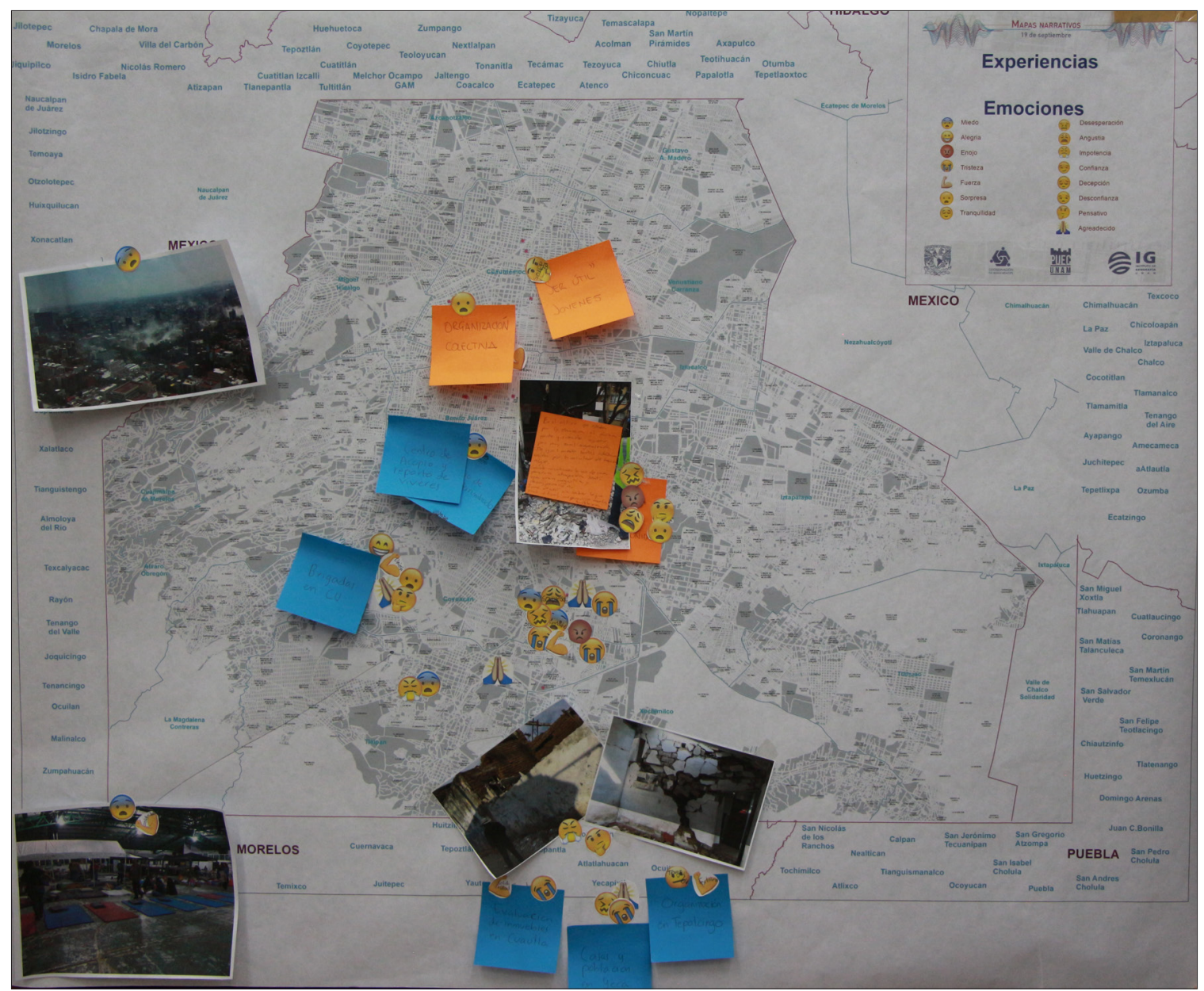

Figura 2: Mapa emocional producido en un taller, con el uso de textos en post-it, fotos y emojis

Fuente: Elaboración propia a partir de los datos del grupo focal (13 de diciembre 2017)

En la tercera etapa, analizamos los datos para visualizar de manera grafica y en cartografía narrativa las trayectorias individuales en donde se representa la cronología del apoyo brindado por la persona, los lugares, así como narrativas de sus emociones por medio de fotografías, citas y escritos que realizaron durante los grupos focales. En estas narrativas se observa la experiencia del participante a partir de sus emociones, sus sentidos (olor, silencio, polvo, etc.) y los motivos que tuvieron para apoyar a la ciudadanía durante el sismo (Figura 3).

El material audiovisual de las sesiones, así como las fotos donadas por los participantes, sirvieron para la elaboración de los videos presentados en los mapas del sitio web, (http://generacion 19s.puec.unam.mx/). ${ }^{25}$ Los videos permiten sentir (percibir las emociones) en la experiencia de los participantes. Por tanto, estos registros de narraciones se sobreponen como una representación visual transversal de la extensión geográfica del apoyo, de la diversidad de acciones, y de la gama de emociones de los participantes en su conjunto.

25 Sitio web con la cartografía y mapas narrativos: http:/generacion19s.puec.unam.mx/ 


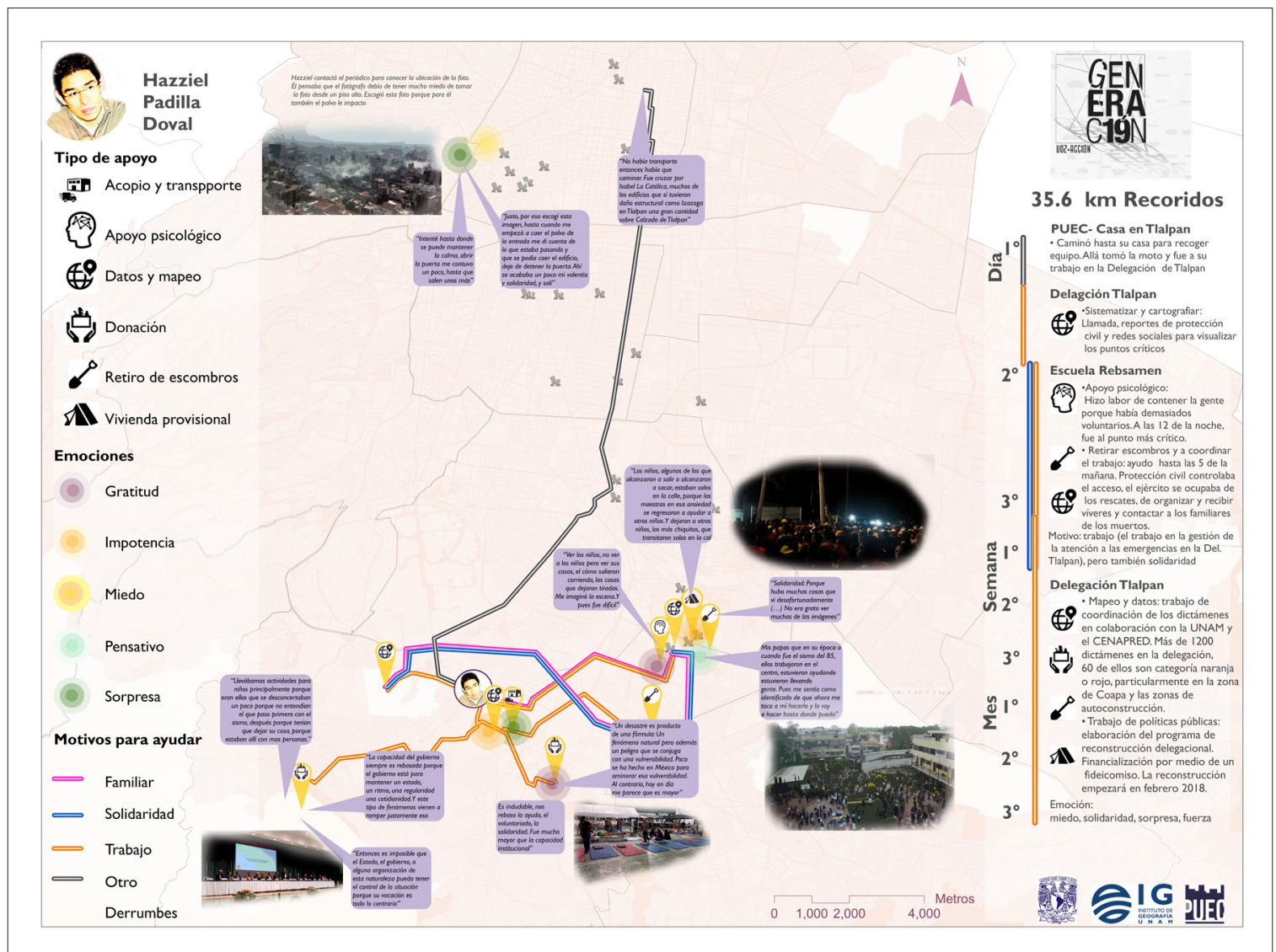

Figura 3. Mapa de trayectoria individual

Fuente: Dinámica del 13 de diciembre 2017. Elaboración: propia

Finalmente, la cartografía narrativa de México producida por los jóvenes urbanos en los días posteriores al sismo del 19S fue presentada en la gran maqueta de la Ciudad de México ${ }^{26}$. El contraste con la cartografía afectiva del sismo y a decir de los asistentes fue bastante fuerte emocionalmente, por ejemplo, los mapas de riesgo que se presentan al tener indicadores complejos para la ciudadanía que no conoce la simbología resultan difíciles de leer (Figura 4a).

Por otro lado la cartografía narrativa, genera una sensación de cercanía para quién observa el mapa, de hecho durante el conversatorio que sigo a la proyección de los mapas, se discutió la importancia de la cartografía afectiva para entender y prevenir futuros desastres, es decir comprender las emociones que están presentes después de un sismo, que marca emocionalmente a las personas y como la solución y el diseño de protocolos de prevención puede disminuir y/o cambiar las emociones relacionadas con el enojo, la frustración y la ira. El evento revelo el uso social de esas visualizaciones (Figura 4b).

26 La escala de la maqueta es de 1:2500 por medio de una producción video con testimonios de los participantes y la proyección de los mapas en la maqueta. El evento empezó con un video-mapping presentando la visión hegemónica de la sismicidad de la ciudad a partir de la geografía física y de los servicios de protección civil. 


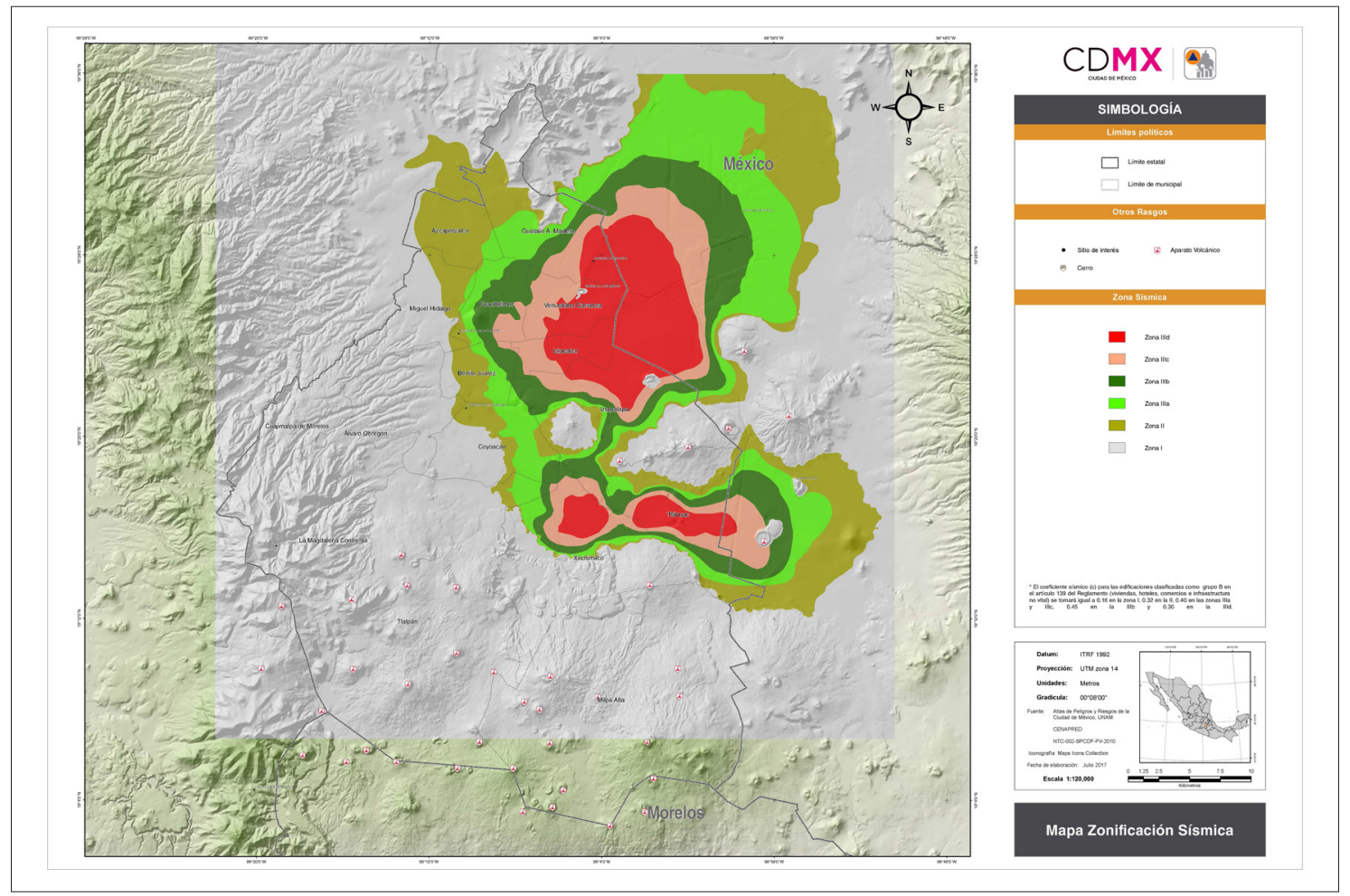

Figura 4a: Mapa tradicional de las zonas sísmicas

Fuente: Ciudad de México, Protección civil: http://data.proteccioncivil.cdmx.gob.mx/mapas_sgm/mapas_sgm2.html

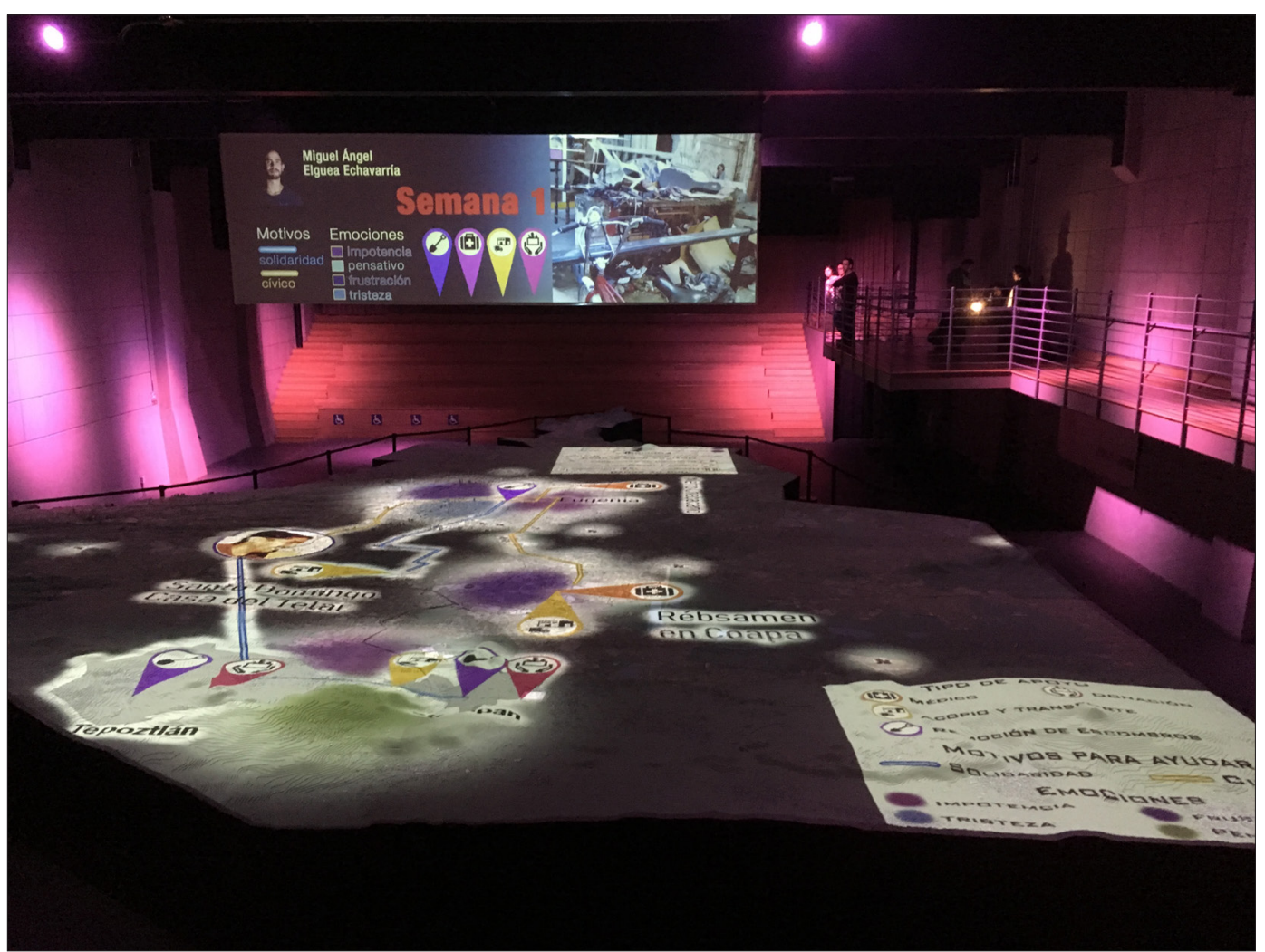

Figura 4b: Proyección de una trayectoria afectiva de voluntarismo con testimonio en audio, en el Centro Interactivo Futura CDMX, 20 de septiembre 2018

Fuente: elaboración propia 
Ahora, es relevante destacar las diferencias entre los mapas tradicionales y los participativos. Por ello, la discusión no solo debe de estar relacionada con la visualización y la representación de los datos, sino también con la forma en que se producen estos y el sentido para las personas que participan en los procesos de recolección. Por lo anterior consideramos al menos dos diferencias que permiten reflexionar sobre la producción de cartografía narrativa y sus implicaciones a nivel de producción de datos, epistémico y de visualización.

La primera diferencia entre los mapas tradicionales y los mapas participativos es que los primeros, muestran información topográfica (tipos de suelos, vulnerabilidad sísmica) y artificiales (vías de comunicación, núcleos de población, límites políticos, económicos, sociales), mientras los mapas participativos presentan el discurso narrativo, el cual unifica la experiencia cotidiana de las personas, son de elaboración colectiva, estimulando los procesos de comunicación entre los participantes.

Siguiendo con la línea planteada, este tipo de mapas se convierten en un instrumento para evaluar procesos que tradicionalmente no son retomados en los mapas

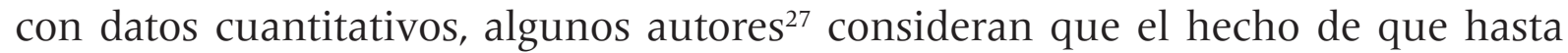
ahora, en ningún momento del proceso de producción de mapas no se incluya la participación del habitante que vive, marca y significa el espacio que habita en escalas no visibles en las abstracciones de los mapas, es debido a que es excluido desde el momento mismo de la producción del conocimiento y en la toma de decisiones porque lo intangible no aparece en las representaciones, cuando debería ser el principal actor en el proceso, por ello la cartografía participativa y narrativa intenta remediar esa situación. Así la cartografía narrativa del sismo permitió visualizar lo experiencial a fin de entender los efectos biográficos, intergeneracionales y en la vida urbana del voluntarismo a partir de la voz de quien vivió el proceso, considerando la experiencia como la primera fuente en la producción de los datos, como una ciencia que aporta una dimensión social. ${ }^{28}$

La segunda diferencia está relacionada con el uso semántico y pragmático de la representación a nivel visual pero también en la comunicación de los mapas ante el usuario final. Algunos autores ${ }^{29}$ han plateado que el llamado mapa científico, solo representaba un objeto neutro en cuanto a valores y significados, por ello en términos de comunicación cartográfica, este tipo de mapas solo sirve como un canal de transmisión de información geográfico-espacial.

En relación con lo anterior, se ha planteado que la elaboración de los mapas es una acción útil para intentar influir en las acciones del usuario. Es decir ${ }^{30}$, desde el plano tradicional "este mapa representa el territorio" y desde una lógica participativa "este mapa crea el territorio" por ello debe de existir una información e interacción entre el cartógrafo y el usuario. Lo anterior se resume en la tabla 1.

27 Wiener Castillo 2017

28 Harley, 2001

29 Zarycki, T. 2001

30 Azócar, P. 2017 
Tabla 1 Oposición entre el mapa semántico y el mapa pragmático (Zarycki 2001)

\begin{tabular}{|c|c|}
\hline Mapa semántico & Mapa pragmático \\
\hline Significado de las formas del mapa & Acción con el uso de las formas del mapa \\
\hline Estable, significado absoluto & Significado contextual \\
\hline Signos & Objetos del mapa \\
\hline Enfoque normativo & Enfoque descriptivo \\
\hline Objetividad, representación & Relatividad, funcionalidad \\
\hline $\begin{array}{l}\text { Transmisión de información, modelo de } \\
\text { comunicación cartográfica en un solo } \\
\text { sentido }\end{array}$ & Interacción social, influencia mutua \\
\hline $\begin{array}{l}\text { El mapa como una herramienta de } \\
\text { descripción de la realidad }\end{array}$ & $\begin{array}{l}\text { El mapa como una forma de creación / ne- } \\
\text { gociación de la realidad. } \\
\text { El mapa como una herramienta de } \\
\text { dominación simbólica }\end{array}$ \\
\hline $\begin{array}{l}\text { Las reglas de la comunicación cartográfica } \\
\text { están dadas objetivamente y deben ser } \\
\text { respetadas }\end{array}$ & $\begin{array}{l}\text { Las reglas que gobiernan la comunicación } \\
\text { cartográfica son inestables y deben ser } \\
\text { establecidas, analizadas y relacionadas a } \\
\text { algún contexto social de su existencia }\end{array}$ \\
\hline $\begin{array}{l}\text { Los mapas son creados por cartógrafos } \\
\text { sobre la base de su conocimiento de la } \\
\text { realidad }\end{array}$ & $\begin{array}{l}\text { Los mapas son diseñados no solo por } \\
\text { aquellos que los hacen, sino también por los } \\
\text { intereses de quienes sirven. }\end{array}$ \\
\hline
\end{tabular}

Fuente: Elaboración a partir de Azócar (2017).

Por lo anterior el proceso que realizamos para la producción de los datos y para visualizar los mapas narrativos, implico no solo generar mecanismos participativos para conocer la experiencia y acción performativa de los jóvenes que realizaron acciones de apoyo después del sismo, sino también usar datos que no son indicadores cuantitativos, como lo son las emociones y su posterior visualización en un mapa.

Esto nos permitió conocer la frustración, enojo y solidaridad de los jóvenes, así como sus efectos a nivel de percepción y apropiación del espacio urbano, dando sentido a la experiencia de construir ciudad desde sus miradas y por otro lado visualizando los efectos del sismo fuera de los derrumbes y la parte material de la ciudad.

Por ejemplo, en la figura 5 se puede identificar el conjunto de las emociones expresadas durante las sesiones de cartografía participativa y los grupos focales, representando aquí la colonia Del Valle. Se puede ver los detalles por emoción, escuchar las narrativas, o ver el mapa a escalas más grandes. Así encontramos que se identificó 16 tipos de emociones diferentes, siendo la impotencia (anaranjado) y el enojo (rojo oscuro) las emociones más mencionadas, seguidas por la tristeza (rojo), pero también la alegría (rosa) de poder colaborar y apoyar a las diferentes comunidades damnificadas. ${ }^{31}$

31 La gama de color corresponde a la clasificación de Kandinsky (1911/2006) para quien el color 


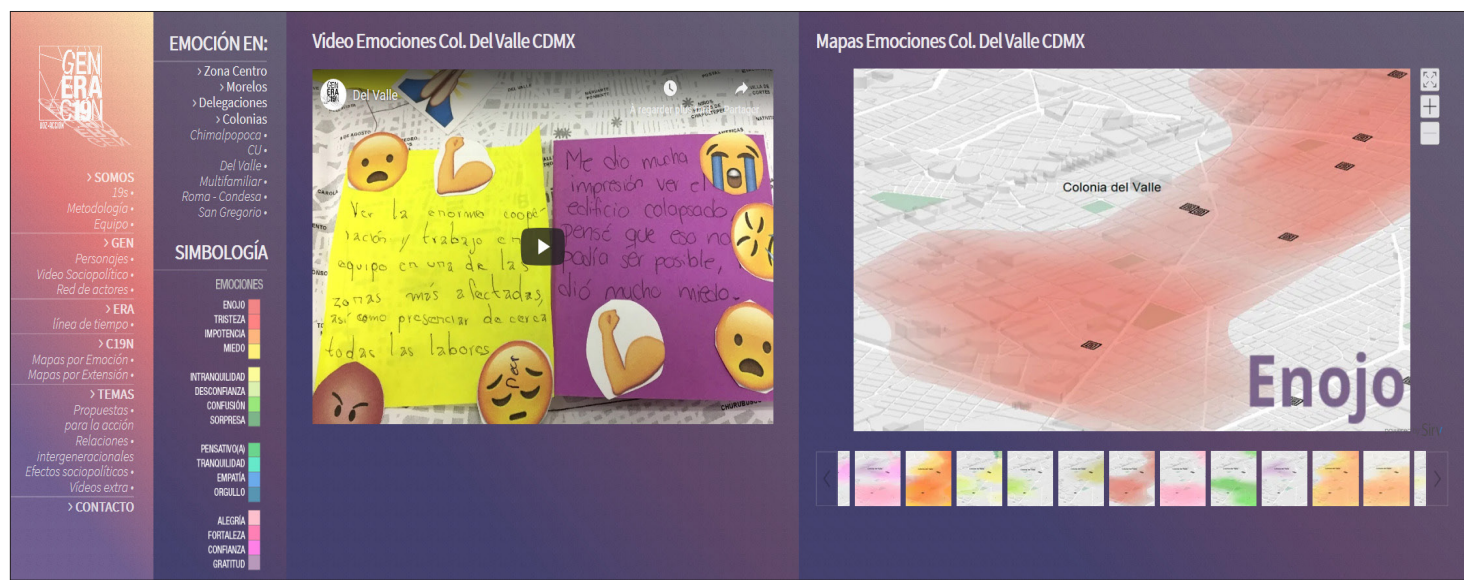

Figura 5: Mapa emocional Del Valle.

Fuente: Dinámicas de cartografía participativa con 45 jóvenes, entre el 8 de noviembre 2017 y el 27 de enero 2018.

Con el proyecto Genera19n, buscamos inventar un lenguaje de comunicación propio de la cartografía afectiva. Era importante mostrar el mapa en sus múltiples iteraciones, primero con caligrafía, audio y emojis durante los talleres (disponibles en los videos), después de manera transversal a todos los participantes con manchas de colores y la ubicación de los derrumbos marcados con cuadritos negros sobre un fondo de mapa tridimensional para ofrecer la perspectiva desde la calle y no desde arriba..$^{32}$ Finalmente, los mapas de trayectoria individual buscan sintetizar por cada participante las variables emocionales, narrativas y temporales, mostrando a la vez las actividades que hicieron usando iconos, la extensión geográfica y la cronología de su labor, los motivos de la acción representado por el color de la líneas del trayecto, y los lugares importantes con su afectividad y narración (a través de colores emocionales, citas y fotos).

\section{Lugares afectivos $19 \mathrm{~S}$}

A manera de ejemplo de cómo se visualiza un mapa narrativo con datos de acciones de apoyo y en que tiempo de dio (Figura 6), cuando se difundió información sobre el colapso de edificios la ayuda desde el primer día se concentró en estos espacios céntricos de la ciudad (en las alcaldías Benito Juárez, Cuauhtémoc y Coyoacán), y el tipo de ayuda fue principalmente para retirar los escombros con la esperanza de salvar vidas, pero también centros de acopio para los damnificados y actividades de mapeo y verificación de la información por medio de las redes sociales (color amarillo). En la semana posterior al sismo (color rosa), el acopio y traslado de víveres y donaciones se extendió a otras entidades federativas. El apoyo comienza a fluir desde el extranjero, mediante el uso de redes sociales como estrategia de comunicación y el envío de donaciones en efectivo como tipo de ayuda.

El tipo de visualización que de manera tradicional se hubiera presentado sería con tablas y mediante frecuencias y con los nombres de los lugares. Al utilizar cartografía narrativa podemos hacer uso de visualizaciones que ayuden a espacializar

es un código capaz de transmitir emociones a quienes los observan.

32 El lenguaje visual desarrollado aquí se inspira primero del trabajo de Christian Nold, 2009 
los datos y para los lectores simplifica las variables a analizar, a la vez de contra una historia sobre los datos y las personas involucradas.

Así podemos observar que durante los primeros días el apoyo se concentro en el centro de la Ciudad de México, pero conforme pasaron los días y la información comenzaba a fluir, el apoyo se fue expandiendo hacía la periferia de la ciudad hasta alcanzar otros estados de México. Así, hacia el mes 3 y 4 la actividad de apoyo estaba focalizada entre el estado de México y el estado de Morelos, muy lejos de donde se dieron los principales muertes (Ciudad de México) y los derrumbes, pero son lugares rurales sin apoyo y con niveles de pobreza más alto al de la Ciudad de México.

Es decir, el mapa narrativo ayuda a contar la historia a nivel temporal y espacial, pero de una manera visual lo cual permite, por un lado, concentrar los datos en una sola imagen y por el otro narrar dos historias la de quién produce los datos (voluntarios) y la del fenómeno que describe (los efectos e impactos del sismo).

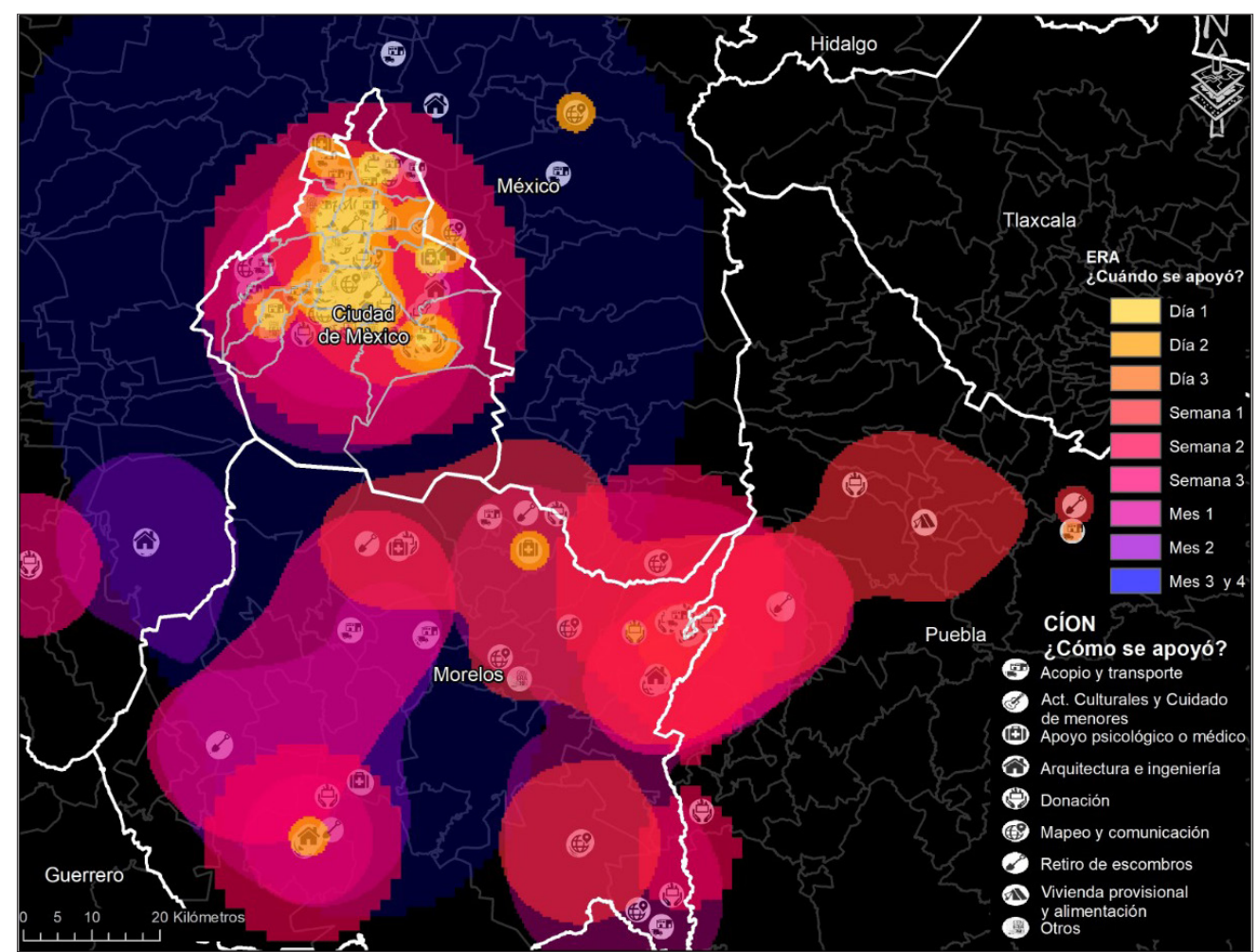

Figura 6: Evolución cronológica del tipo de apoyo y extensión geográfica de las actividades

Fuente: Dinámicas de cartografía participativa con 45 jóvenes, entre el 8 de noviembre 2017 y el 27 de enero

La extensión geográfica de la labor de los voluntarios y su constante movilidad es una diferencia importante con la generación de 1985, cuando la ayuda era micro-local y estacionaria. Por lo tanto, esa movilidad no significo la ausencia de lugares significativos. Al contrario, los recorridos entre lugares significativos permitieron articular escalas y construir un imaginario solidario de la ciudad en reconstrucción física y simbólica.

Dos semanas después del sismo, el regreso a las actividades educativas y labora- 
les cotidianas significó una reducción en la intensidad de las actividades de apoyo. Sin embargo, durante este periodo se consolidaron actividades culturales, de atención y cuidado de menores. Las actividades de apoyo se focalizan fuera de la Ciudad de México, pues en algunas localidades continúa la remoción de escombros. Tres meses después del sismo, son pocos los lugares dentro de la Ciudad de México que se mantienen activos (color azul). Sin embargo, hay puntos estratégicos que continúan llevando acopio, ayudando en la remoción de escombros, y en la reconstrucción de viviendas en los estados de Morelos, Puebla y Oaxaca. Al final, si la actividad de apoyo paro, los lugares se mantienen vivos en la memoria de los voluntarios y habitantes. En este sentido, la Generación 19S construyo una "nueva" ciudad, física y simbólicamente.

El siguiente recorrido de esos lugares afectivos empieza con la exploración del centro de la ciudad, pasando por la zona Sur y para terminar las redes sociales (Figura 7).

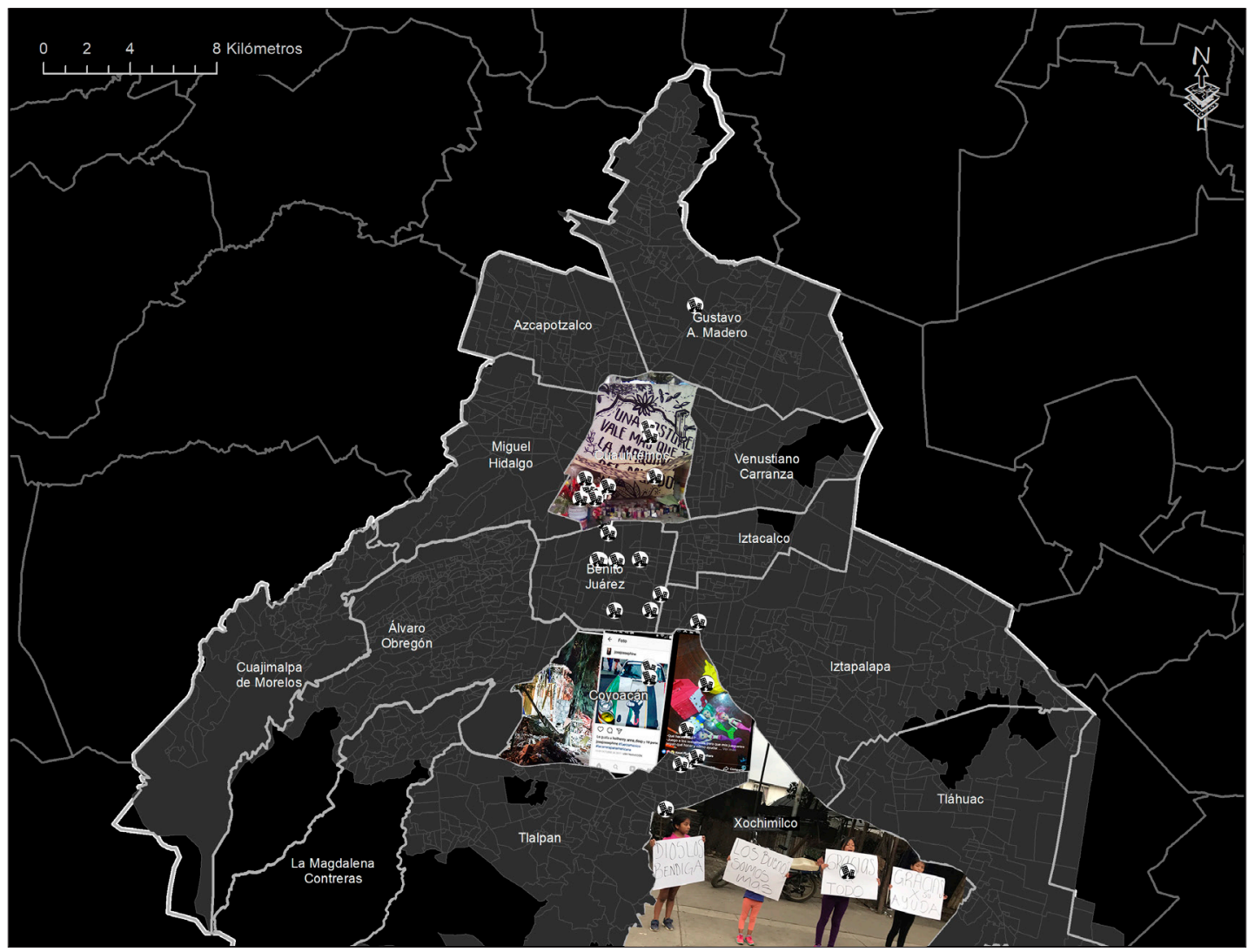

Figura 7: Lugares afectivos

Fuente: Dinámicas de cartografía participativa con 45 jóvenes, entre el 8 de noviembre 2017 y el 27 de enero 2018. Elaboración propia

En la figura 7 se puede observar las imágenes que fueron representativas para los voluntarios, así como el lugar al que estaban vinculados. Con este tipo de representación se vincula la experiencia visual con el lugar en un mismo mapa de la ciudad, en el siguiente apartado se analizarán las emociones y el vinculo con el lugar para los voluntarios. 


\section{El centro}

Quizá el lugar más significativo de la zona centro de la Ciudad es la calle Chimalpopoca. Es un lugar emblemático para los voluntarios del sismo porque se ubica una fábrica que se mantenía en funcionamiento a pesar de las distintas irregularidades que presentaba desde 2004, cuando el Centro Nacional de Prevención de Desastres (Cenapred) sugirió su demolición por incumplir las normas de seguridad. La fábrica no era un lugar desconocido ni aislado, desde el terremoto de 1985 cuando varios inmuebles en la zona colapsaron, las costureras sobrevivientes al sismo formaron un sindicato en busca de mejores condiciones laborales. En 2017 se repitió la historia, al menos 21 personas murieron en el lugar (figura 8).

Eso genero mucho enojo por parte de los voluntarios, en especial mujeres feministas, debido al "rumor" de que había costureras atrapadas en lo que era el sótano del inmueble. Así, Diana expresa "Estuve la primer semana en Chimalpopoca hasta que llegó a quitarnos la policía a todos los voluntarios [...] estuve haciendo colaboraciones para varios diarios sin permiso del ejército que estaba sobre nosotros todo el tiempo. Sentí un gran enojo e indignación"

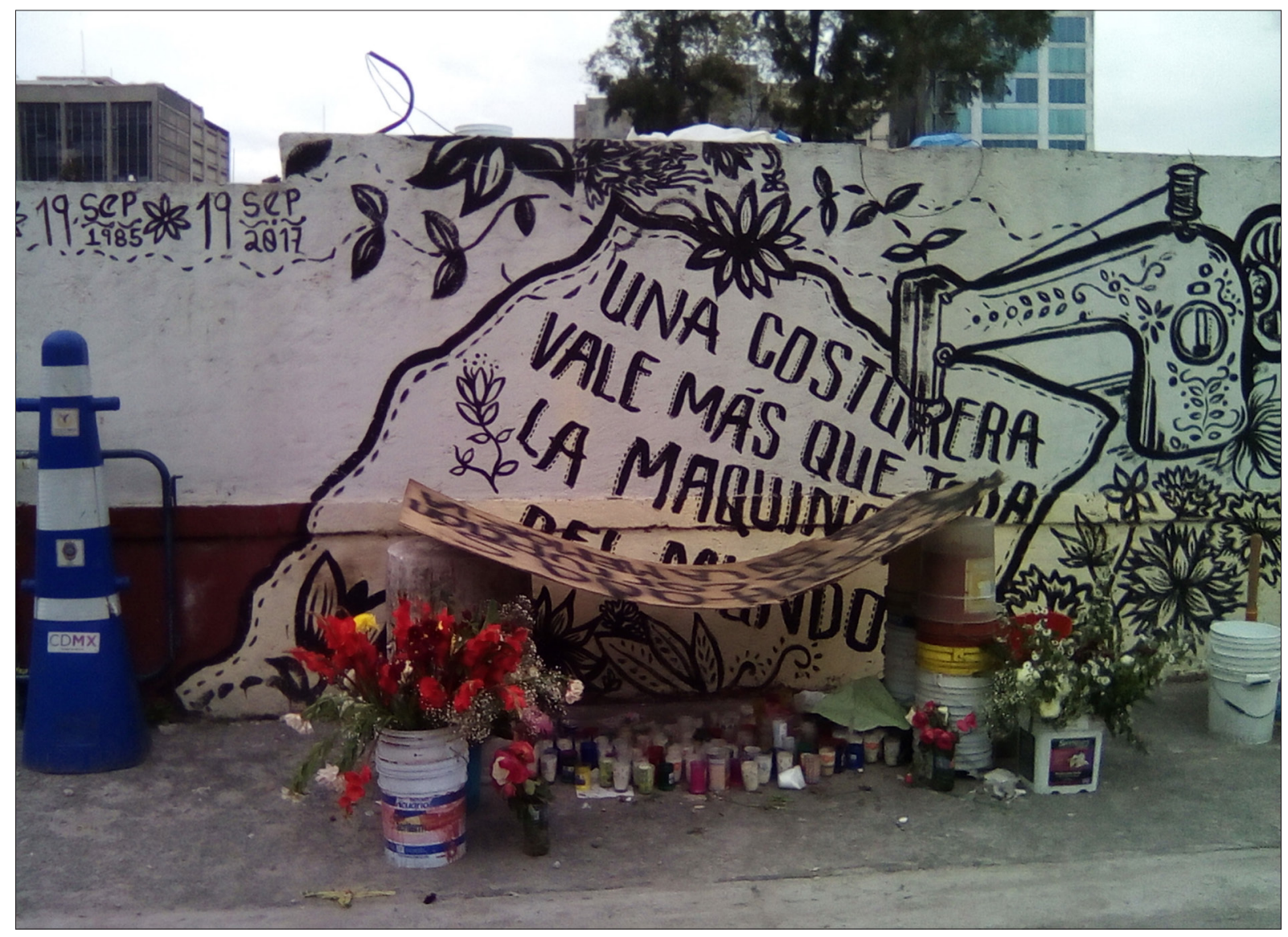

Figura 8: Altar a las costureras fallecidas Fuente: Julio César Navarro Becerril

Hubo una disputa por el espacio, pues después de horas de realizar labores de rescate por civiles, la llegada del ejército no fue bien recibido por los voluntarios, se mencionó que su trabajo no era colaborativo, si no que más bien buscó romper todo 
tipo de organización antes de su llegada. Sebastián ejemplifica esto:

En Chimalpopoca yo creo que lo más importante es el enojo [...] llegamos y el primer día la gente se organizó de buena manera, había muchos retenes civiles por parte de boy scouts a los que la policía y los militares les dieron el poder de organizar, ellos decidían quiénes podían pasar y quienes no; pero ya conocemos al Estado y sabemos para qué está y cómo funciona y cómo es el responsable de todo esto que pasó, desde lo económico, por qué hay una ciudad de 20 millones de habitantes sobre un lago, mil cuestiones del capitalismo.

Ligeramente al este de la fábrica se encuentran las colonias Roma, Roma Norte, Condesa e Hipódromo Condesa, durante la emergencia era nombrada Roma-Condesa, dentro de las cuales hubo 8 edificios colapsados y otras decenas más dañados. El perfil de las personas que habitan estas colonias es de clase media, media alta. Después del sismo, al darse a conocer los daños que hubo, generó una respuesta desbordada por parte de los voluntarios. Julio César menciona "En esos día estuve recorriendo puntos en la calle de Coahuila que fue donde se cayó un edificio súbitamente. Ahi me tocó pasar una noche, me sorprendió la presencia del ejército y la cantidad de material que ya se habia juntado." José agrega: "Fue difícil no sólo para los habitantes, también para algunos obreros que estaban trabajando en la construcción de un edificio cerca del Parque México, eran gente de Michoacán que se estaban quedando ahí mismo en la obra y se les dio albergue después de que se canceló la obra posterior al sismo".

Como en Chimalpopoca, los sentimientos recurrentes en la Roma-Condesa por parte de las personas entrevistadas fueron la fortaleza y la alegría de ver tanto apoyo en las calles, pero también el enojo y frustración al ver el actuar de las autoridades a través de las fuerzas armadas que iban a deshacer cualquier tipo de organización civil antes de su llegada. Los voluntarios manifestaron que les parecía que el gobierno estaba temeroso de que sucediera como en 1985 cuando a partir del sismo y la organización civil, distintos movimientos sociales fueron fortalecidos por el lento actuar del gobierno. Evelyn lo ejemplifica de esta manera "Fui a la Condesa por el parque España, pero como habia mucha gente por lo que nos mandaron a otro lugar que estaba por Medellín, [...] cuando estaba ahí, llegó la Marina y empezó a decir que todos nos retiramos pues ellos ya estaban ahi".

Hacia el sur de la Roma-Condesa se encuentran las colonias Del Valle Centro, Del Valle Norte y Letrán Valle en la alcaldía Benito Juárez. En estas colonias la población es también principalmente de clase media y media-alta. En su mayoría son edificios de uso habitacional y de oficina. Después del 19 de septiembre de 2017, muchos de los voluntarios que llegaron a los edificios colapsados buscando apoyar de alguna manera provenían de Ciudad Universitaria debido a su cercanía con la Universidad Nacional Autónoma de México (UNAM). Para Sebastián queda claro:

Había una hilera de personas que estábamos sacando escombros, cuando alguien iba a salir a alguien pedían que guardáramos silencio y aplaudían si sacaban a alguien. Fue un momento muy raro porque iban a sacar a alguien en una camilla, era un niño y la gente comenzó a aplaudir, yo volteé porque me dio curiosidad y vi que el niño estaba muerto, la gente no se dio cuenta. Esas cosas te dan fuerza, piensas en que puede haber más gente bajo los escombros y te da energía [...] Hice una pausa y volteé al edificio de al lado y vi una señora que re- 
cién había salido de bañarse, aún tenía la toalla en la cabeza, quitada de la pena. Es increíble cómo puede estar ahí al lado de un edificio de 10 pisos que se acaba de caer y ella campante bañándose.

La zona central ha recibido la mayor parte de la atención inmediata tanto de las autoridades como de los civiles, y se caracteriza por tensiones y emociones conflictivas. ¿Quién podrá reconstruir estos lugares? Para Mariana y Miguel mencionan como sus emociones fueron contradictorias en los mismos lugares, estas dependían más de lo que sucedía en el tiempo. Marina dice: "Al inicio el sentimiento fue de shock, después en realidad alivio, en ese momento fue regresar y volver a confiar en la gente. Alegría, gusto por ver el esfuerzo de toda la gente. Sentí también frustración porque éramos demasiados y nadie se quería ir a pesar de que nos estábamos estorbando" Miguel lo expresa así: "Mucha era la presión por intentar hacer lo necesario por sacar a las personas, habia ocasiones en las que no es posible sin embargo no por eso no se debe de dejar de apoyar"

En lugares como Chimalpopoca, la Roma-Condesa o la colonia Del Valle, se ubican una multiplicidad de formas de política cultural (Escobar y Pedroza, 1996), en este caso, un conflicto abierto entre las autoridades de la protección civil y los voluntarios espontáneos que llegaron para apoyar y construir nuevos lugares, nuevos significados.

\section{El sur}

La zona del sur de la Ciudad de México fue la más cercana al epicentro. Cuatro lugares fueron importantes para los jóvenes voluntarios por distintos motivos: Ciudad Universitaria de la UNAM como punto de encuentro y organización de la ayuda, el Colegio Rébsamen donde la mayoría de los afectados fue la niñez (era horario escolar), San Gregorio (Xochimilco) y el multifamiliar Tlalpan por sus derrumbes.

Dado que la mayoría de los participantes entrevistados son estudiantes, Ciudad Universitaria fue de gran importancia. Por ejemplo, el 19 de septiembre, el Rector emitió una convocatoria convocando a estudiantes y público en general a reunirse en el Estadio Olímpico de la UNAM. A las 8:00 p.m., había miles de personas. Varios participantes expresaron sorpresa y orgullo. "Habia una infinidad de brigadas de veinte personas. Cada dos minutos salía una brigada. iHabia un montón;," mencionó Marco, i"parecía hasta que había un partido de fútbol!" El Estadio Olímpico fue lugar de uno de los centro de organización y acopio más grandes en la ciudad.

Pero no solo fue la organización y envío de apoyo, si no la capacitación para supervisar las casas e inmuebles, alrededor de 4000 estudiantes dieron algún tipo de apoyo de acuerdo con el perfil de sus carreras. Las brigadas de la UNAM respondieron a unas 1700 solicitudes para el dictamen de casas. Como lo explica Joanna, "mi trabajo era ver [las casas], pero era más hacerle saber a la gente que la Universidad estaba con ellos, la gente nos decía que como éramos de la UNAM, estaban tranquilos." La reputación de la UNAM y la responsabilidad profesional motivó a muchos en participar en las brigadas: "para aportar mis conocimientos y habilidades." Pero para 
muchos, "querer apoyar y ser héroes" no es suficiente; Raúl noto que "esto no es una crisis que se pare en un dia; es algo que dura". Se tenía que mantener la movilización inicial, y eso no era fácil. Por un lado, muchos sintieron impotencia por no poder salir de inmediato a apoyar: "En la capacitación en CU, fue difícil y un poco agresiva la reacción colectiva porque todos se desesperaron y querian salir lo antes posible a ayudary sentían que el tiempo era muy valioso. Se perdió un momento el control y al final la parte de primeros auxilios psicológicos nos calmó un poco y nos pidió considerar esta situación de estrés con las personas que ayudáramos" (post-it, mapa emocional, 22 noviembre 2017)

Quizá el lugar más emblemático por el número de fallecidos en un mismo lugar y por cuestiones mediáticas fue el Colegio Rébsamen, una primaria donde murieron 18 niños y 7 adultos. Como se puede observar en el mapa de Hazziel, un empleado en la Delegación Tlalpan, cuando supo del Rébsamen, salió de inmediato para apoyar en la coordinación de los trabajos de rescate Figura 3). Él recuerda:

Pues no era grato [...] ver a los niños, o no, pero ver sus cosas [mochilas, material de escuela], el cómo salieron corriendo, las cosas que dejaron tiradas. O sea, me imaginé la escena. Y pues fue difícil [...] Los niños, algunos de los que alcanzaron a salir o alcanzaron a sacar, estaban solos en la calle, porque las maestras en esa ansiedad se regresaron a ayudar a otros niños dejaron a otros niños, los más chiquitos, que transitaron solos en la calle.

Hacia el Sur de la ciudad, en la Alcaldía de Xochimilco, en el pueblo de San Gregorio Atlapulco fue de los más afectados. La noticia de lo ocurrido se supo hasta el día siguiente y fue por medio de las redes sociales, muchos voluntarios se trasladaron hacia Xochimilco, lo que generó tráfico automovilístico, dificultando la llegada de voluntarios. María refiere cómo se sentía alegre porque: "Logré bajar y subí por el cerro y pasar alimento para bebé. Fue lo más significativo para mi porque logramos llevarla directamente a las personas, porque la demás estaban embodegando y no sabiamos si era confiable." Por su parte, Itzel recuerda su enojo porque había gente que no necesitaba ayuda y que estaban formarse para recibir la despensa, mientras otros tienen necesidades muy fuertes. Es significativo que parte de los recuerdos de los voluntarios fue el afecto con el que los trataron los damnificados, "nos daban de comer", "nos abrazaban", "no entendiamos que a pesar de perder todo, nos daban algo" (figura 9).

Otro lugar significativo en la zona Sur fue el multifamiliar Tlalpan, una unidad habitacional construida por el Instituto de Seguridad y Servicios Sociales de los Trabajadores del Estado (ISSSTE) en 1957. El 19 de septiembre 2017, el edificio 1C colapso y 9 edificios fueron declarados inhabitables. Nueve personas perdieron la vida ese día y 18 fueron rescatados con vida. Una de las mujeres que colaboró fue Frida. Vive en la colonia de al lado, justo atrás del Multifamiliar. Cuando se enteró que había colapsado, se puso a trabajar. La llamaron la "hormiga atómica":

"En menos de lo que me di cuenta, ya estaba involucrada en organización de voluntarios, transmisiones en vivo, recibir donaciones [...] Después entendí que Julián y Ximena ya no estaban. Conozco a Mayeli (su mamá) pero no la contacté. No sabía que decirle" 


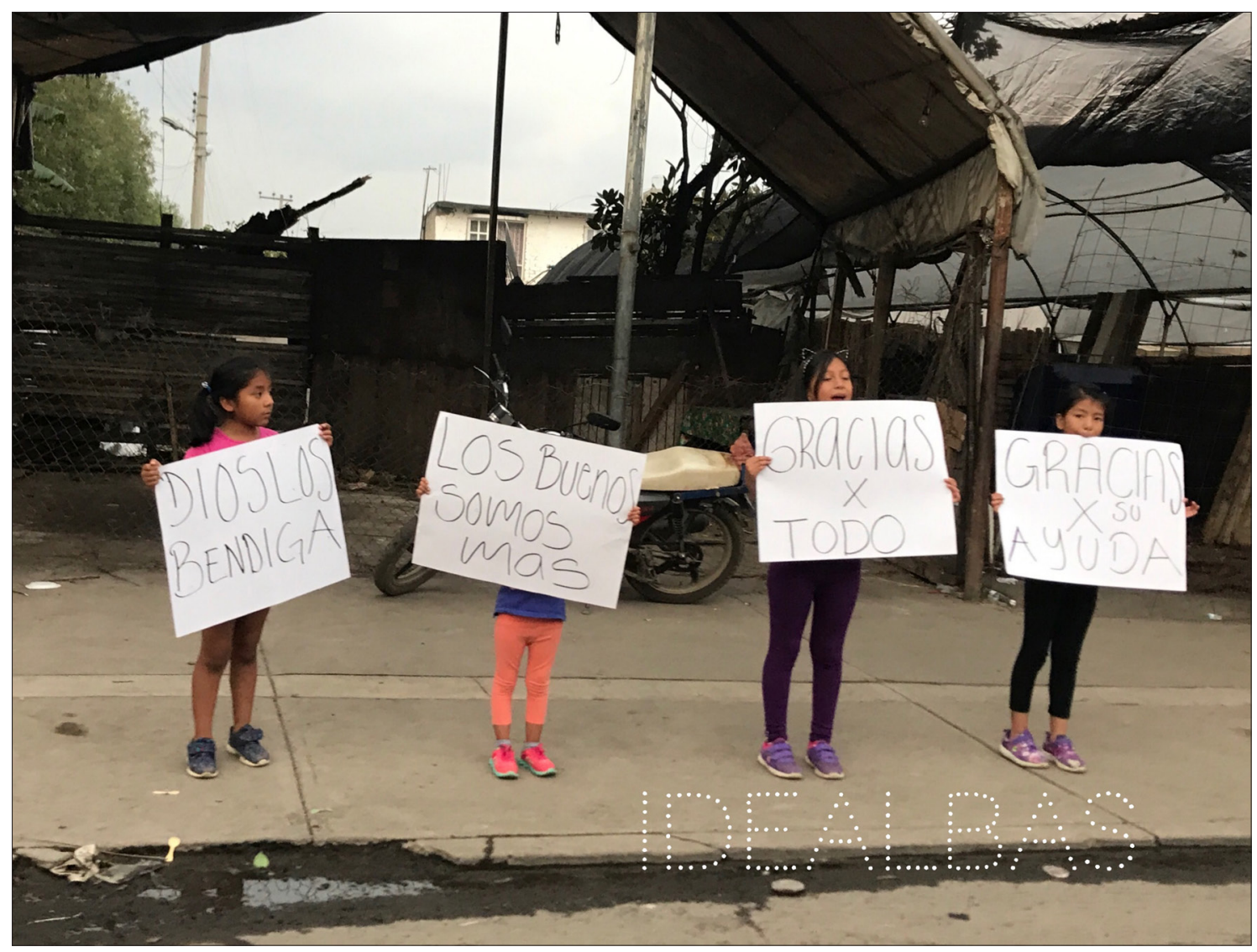

Figura 9: Agradecimiento en San Gregorio Fuente: Itzel de Alba. 2017

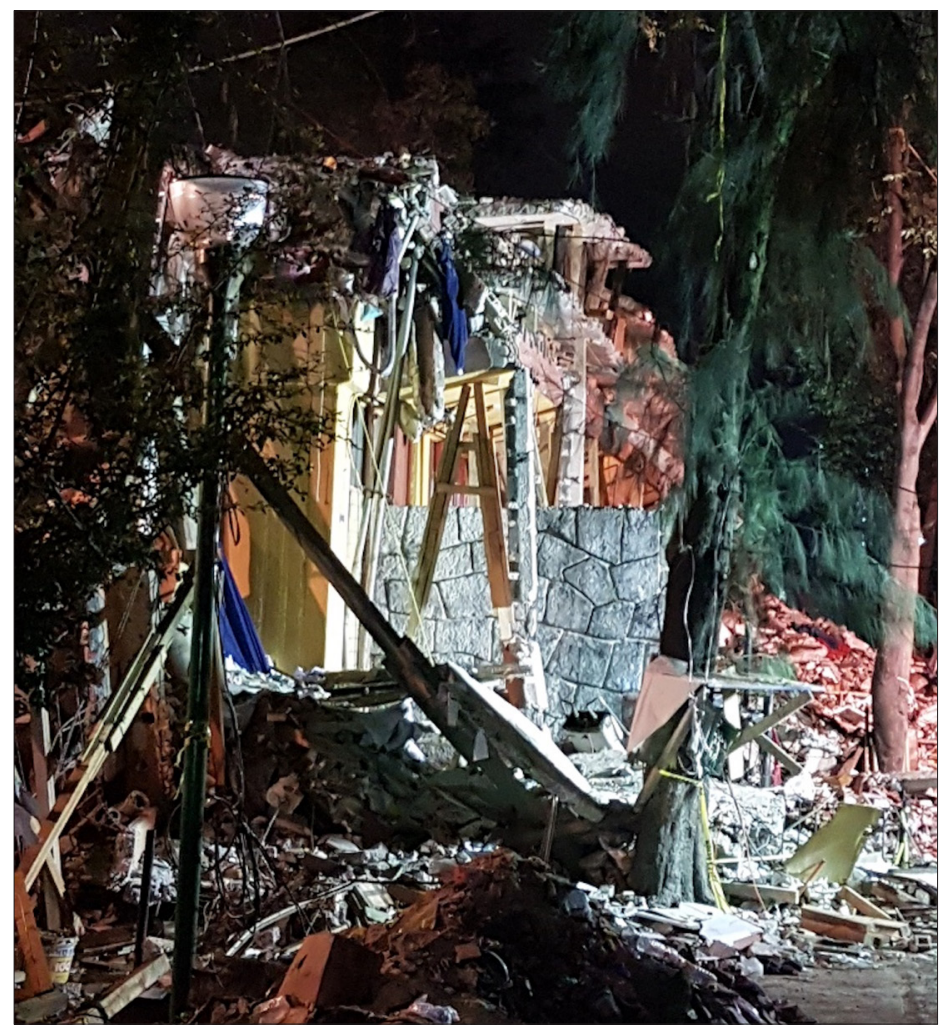

Figura 10: Ximena estaba patinando Multifamiliar Tlalpan Fuente: Frida Hernández 
Esta cita se tomó de la carta manuscrita de Frida, del 27 de enero de 2018. Durante la dinámica de cartografía narrativa, ella recordó: "Justo el viernes, Ximena estaba patinando aqui en las canchas" (figura 10). "Y ahora esto es, esto es lo que hay (27 de enero 2018),

"no se porque no han quitado los escombros. Urge que quiten los escombros. Porque no solo es la limpieza de escombros. Es que incluso si tú pasas sobre Tlalpan, todavía hay pedazos de tela, y cachos de bicicletas en los árboles. Es muy doloroso ver que ahí estaba la vida de las personas, sus cosas. Todo."

Dolor e impotencia es algo que expreso también Mariana:

Perdieron todo los señores. Y entonces sentí mucha impotencia porque no les puedes ayudar. Y ellos estaban muy tranquilos. Pero tú hasta quieres como quitarte las cosas que traes y pues dárselas. Y aparte también por la misma impotencia no puedes (llorando) tenías como que ver a la cara de las personas, y tú no podías llorar porque se suponía que tú eras el fuerte. Y tragar todos estos sentimientos para poder ayudarlos y hacer tu trabajo bien.

Estos lugares en la zona Sur ilustran la transición del ritmo espontáneo inicial al ritmo más organizado del lugar, y el dolor causado por el paso del tiempo. Estos lugares producen sujetos, como la hormiga atómica.

\section{Los estados}

De acuerdo con los informes oficiales ${ }^{33}$, por el sismo del 19 de septiembre del 2017 se identificaron 169,859 viviendas dañadas, ubicadas en las localidades rurales y urbanas de los estados de Chiapas, Guerrero, México, Morelos, Puebla, Oaxaca y en la Ciudad de México, de las cuales sólo 5,961, equivalentes a menos del 5 por ciento de las viviendas dañadas correspondieron con la capital. Esto es significativo para nuestro análisis, ya que, en el discurso público, la participación de los jóvenes fue entendida, en primer lugar, como urbana. Además, son las juventudes urbanas los que dominan en las representaciones generales de la juventud. Sin embargo, los jóvenes que conocimos en esta investigación abandonaron la ciudad, acercándose a su urbanidad en áreas rurales y pobres. Las acciones de apoyo ocurrieron en su mayoría en la zona central de la ciudad, pasados los días los jóvenes observaron una visible concentración de la ayuda en el centro, como lo menciona Miguel "Nos dimos cuenta de que todo estaba bastante sobrado de manos, decidimos ver qué estaba ocurriendo en la parte de Morelos". Así, además de realizar actividades de apoyo en la CDMX, 41 por ciento de los participantes en la investigación se trasladó a otras entidades federativas afectadas por los sismos.

Entre los traslados de apoyo realizados fuera la Ciudad de México, el 45 por ciento tuvieron como destino el Estado de Morelos, donde se comenzó a recibir apoyo un día después del 19 de septiembre y se observó continuidad hasta cuatro meses después del suceso. En segundo y tercer lugar se realizaron viajes al Estado de Mé-

33 http://www.atlasnacionalderiesgos.gob.mx/archivo/eventos.html revisada el 24 de Octubre del 2018. 
xico (24\%) y a Puebla ( $18 \%)$. Cabe destacar que el 8 por ciento de nuestra muestra se dirigió a localidades de Oaxaca a pesar de la distancia y tiempo de traslado entre el estado y la ciudad.

Las actividades que los voluntarios realizaron con mayor frecuencia fueron la donación de víveres, herramientas, ropa, medicamentos o efectivo, seguido del acopio y transporte, así como del mapeo, la recolección de datos y la comunicación de la información. Esta amplia gama de actividades fue posible ante la intención de los jóvenes, principalmente los universitarios, de apoyar desde sus perfiles profesionales, que como lo narra María "Organizamos una brigada multidisciplinar por parte de la facultad, éramos geólogos, físicos, abogados. Fuimos a Morelos a Zacualpan de Amilpas"- permitió la colaboración y el acercamiento entre distintas disciplinas. Ya en el lugar María recuerda como la percepción de insuficiencia para responder ante la crisis fue una constante entre quienes decidieron trasladarse a las zonas rurales. "Nos coordinamos con el señor de protección civil [...] porque fueron muchas viviendas dañadas, no se daban abasto".

En este sentido los motivos de las acciones de los jóvenes fue la solidaridad, convicción que traslada más allá de los límites de la ciudad al extender sus acciones en otros estados. Como estos lugares eran desconocidos para ellos, el impacto emocional que los jóvenes voluntarios experimentaron estuvo relacionado a un proceso reflexivo, así se encontraron pensativos sobre los acontecimientos, los impactos y la manera de apoyar, seguido de momentos de frustración, pero también de gratitud ante el recibimiento en los poblados afectados. Por ejemplo, Miguel relata:

\begin{abstract}
En Totolapan (Morelos) la situación sí era súper complicada. De cierta manera en la ciudad suponíamos que las personas no estaban tan desamparadas, de alguna u otra manera iban a poder tener acceso a víveres, pero acá la situación era más complicada: casas con pérdidas totales y también dejaba ver una complicación de nuestro país, la gente ha tenido situación difícil más allá del sismo, todos necesitaban ayuda" [... " ¿Cómo distingues? ¿A quién le das ayuda? ¿Quién la necesita? Traíamos la ayuda, pero no sabiamos qué hacer con ella.
\end{abstract}

De manera similar, Marina B. se sorprendió que "a pesar de que habian perdido todo, te ofrecian cosas, [...] perdieron todo y están dispuestos a darte, eso es muy intenso. Creo que ellos era lo que te podrian dar, ellos nos dijeron: no podemos darte para tus pasajes, para la gasolina y nos duele mucho, lo que podemos darte es comida".

La experiencia estuvo fuertemente vinculada a las necesidades y desigualdad social que existen en las zonas rurales del país, donde se observó que la pobreza y los daños por los sismos anteriores siguen sin resolverse, pues la respuesta del Estado es tardía o no llega. Esta experiencia fuera de la ciudad acentúa el carácter urbano de las formas de acción sociopolítica de los jóvenes. En este caso, los lugares fuera de la "ciudad" han dejado su huella en los jóvenes a través del descubrimiento del Otro. Los intercambios rurales-urbanos produjeron lugareños híbridos, a través del encuentro (Figura 11 ). 


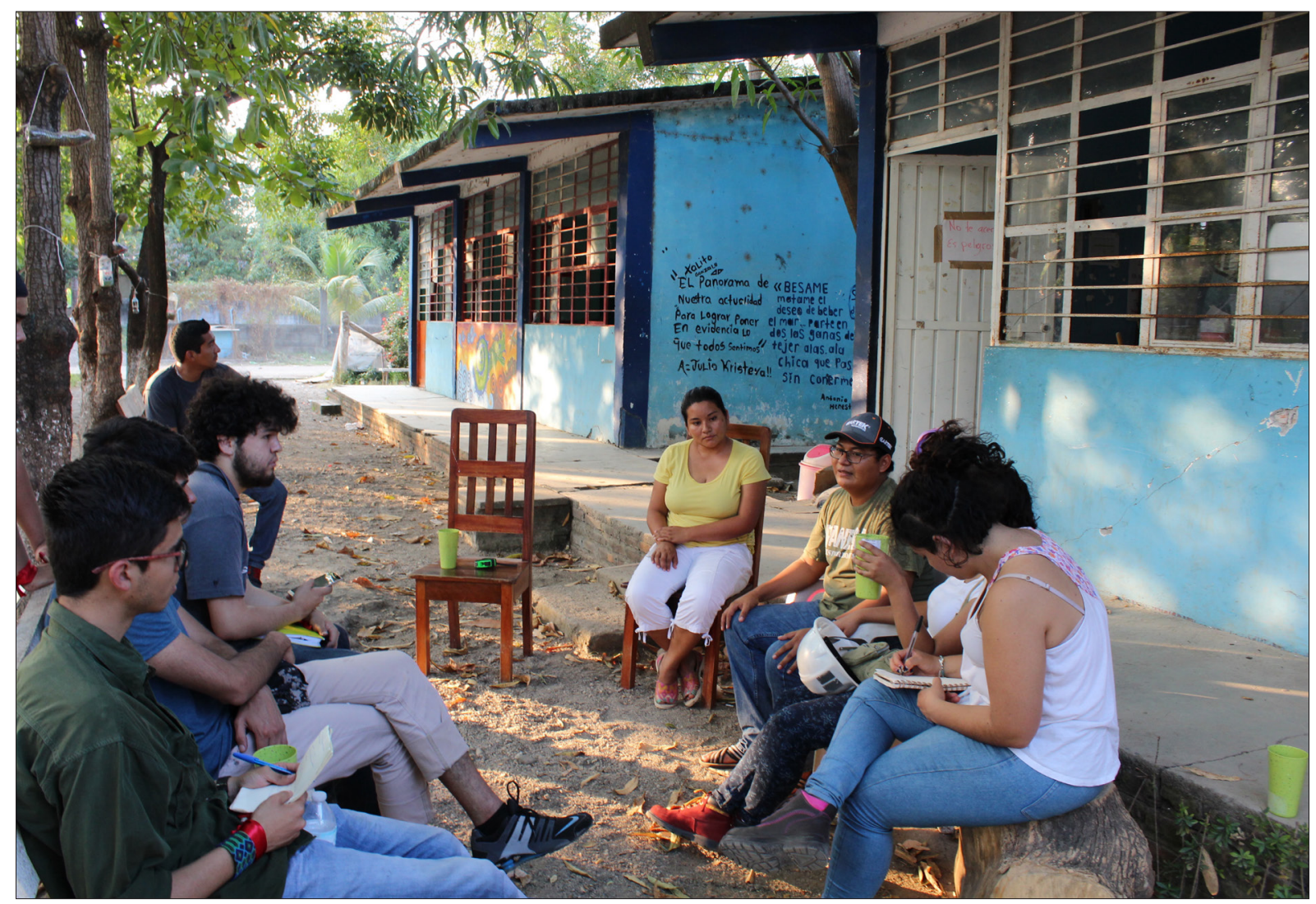

Figura 11: Encuentro de voluntarios con habitantes de una zona rural.

Fuente: Eduardo Olmos, 2017.

\section{El internet}

Consideramos que el uso de la tecnología para los jóvenes que realizaron labores de apoyo después del sismo fue fundamental, ya sea para la organización de la ayuda, comunicarse o generar vínculos con la ciudadanía, por ello lo consideramos un lugar para ellos, no solo una herramienta ${ }^{34}$. Algunos autores describen como el Internet debe de considerarse un lugar afectivo:

... la conexión online no solo es racional sino afectiva, lo cual convoca de manera mucho más acelerada, a las personas que están pensando y sintiendo lo mismo en un momento dado; esto, combinado con las posibilidades de inmediatez e hipertextualidad de la red, da como resultado una mayor probabilidad de "conectar" on y offline la experiencia de millones de personas. $^{35}$

En la figura 12 se observa cómo se usaron las redes sociales para conocer, convencer y/o interactuar con otras personas en ambientes virtuales. El Internet era considerado un lugar afectivo. Por ejemplo, la foto de Nadi "jugando a los rescatistas" dio fuerza a los que estaban haciendo la labor en la ciudad "de verdad".

Los jóvenes realizaron su labor de apoyo de manera individual o colectiva apoyándose de las tecnologías de la información (TIC's), es decir de teléfonos inteligen-

34 Salgado, 2018

35 Abrego, 2018, p. 202 


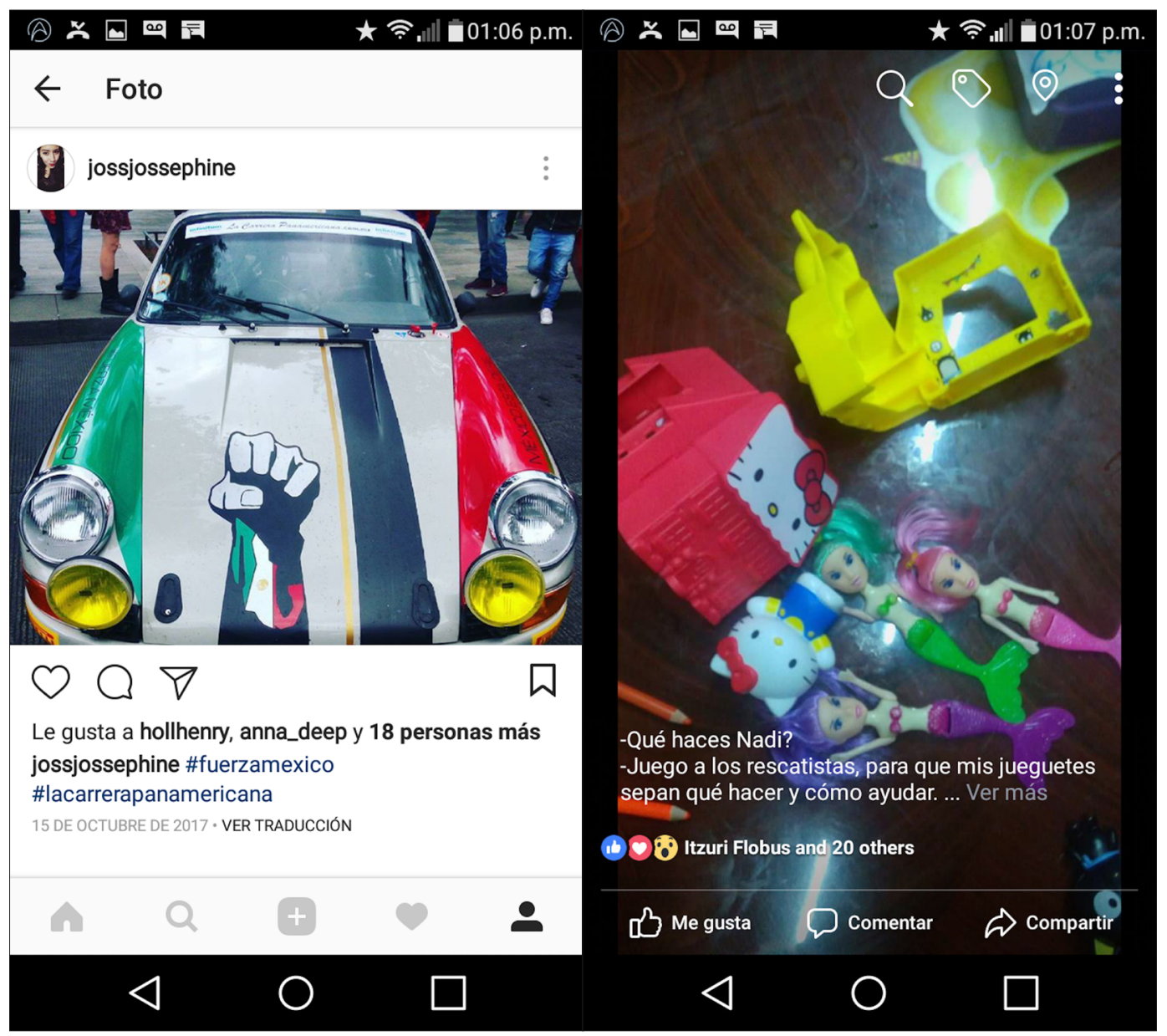

Figura 12: Uso de redes sociales

Fuente: integrante de los grupos focales. Jocelyn 2017.

tes, aplicaciones web, sistemas de información geográfica, redes sociales, computadoras portátiles y las conexiones a redes móviles para el uso de datos para producir datos y contenidos audiovisuales que les permitiera estar organizados en tiempo real. El caso de Itzel es ejemplificativo:

Decidí caminar hacia mi casa después del temblor [...] como periodista tenía que estar al tanto de las redes sociales pero no sabía que pasaba en el centro histórico y sobre Insurgentes comencé a realizar reportes en vivo (Facebook Live) eso me generaba ansiedad, hice la transmisión para que la gente supiera que había tráfico y que los servicios de emergencia lo supiera [...] al transmitir y solicitar ayuda, mis amigos me hablaban y me depositaban dinero para que fuera a comprar lámparas [...] para ofrecer servicios de agua, baño, lo que necesitaran en mi casa, eso lo hice vía Twitter.

A pesar del uso generalizado de las TIC's en la vida cotidiana de los jóvenes, ellos no dejaban de tener interacción cara a cara y sobre todo en lugares claves para poder realizar su labor de apoyo; estos sitios podrían ser parques, aulas de universidades, casas o campamentos, por ello no existió una desfase entre el trabajo presencial y virtual. Adriana explica esa interrelación entre lugar digital y lugar físico:

Cuando estaba abajo del departamento, en ese momento del temblor todos mis amigos de Guadalajara me empezaron a escribir por WhatsApp, así mensajes de ¡Adriana ven i¿no te pasó nada? ¡Dicen que estuvo súper fuerte, no te quedes en la calle, en la Narvarte se están cayendo edificios ¡Para mi fue sencillo, me puse en contacto con mis tíos, con mis amigos y ya 
[...]Lo que hice en casa de mi amiga es ver que se decía en las redes sociales, cómo apoyamos, qué es verdad y que no, informarnos de la situación"

Las tecnologías de la información se usaron de manera natural por parte de las juventudes durante y después del sismo, del trabajo realizado con los 45 voluntarios rescatamos al menos tres usos. El primer uso estuvo relacionado con comunicarse con familiares y amigos para saber si estaban bien y/o avisar que ellos se encontraban bien, la comunicación se dio por medio de llamadas con teléfonos móviles (celulares) o vía texto por medio de aplicaciones de mensajería (WhatsApp, Messenger de Facebook). Por ejemplo, Jocelyn explica: "El día del sismo estaba en mi casa y mi vecina es peruana, estaba asustada por que su esposo trabaja en el centro y no carga celular (teléfono) y como no habia comunicación no sabiamos que había pasado".

El segundo uso está relacionado con procesos que permitieron una alta participación de la ciudadanía, es decir, organizar la ayuda (por ejemplo, cuáles eran los lugares que necesitaban ayuda, en cuales estaba ya cubierta) y dirigirla hacia los lugares que se necesitaba como instrumentos de construcción, medicamentos, alimentos, ropa y víveres. Mariana nota: "Enviaba brigadas a toda la ciudad a Coquimbo (Gustavo A. Madero) Narvarte, etc. [...] nunca habia tenido tantos Whats App en mi vida, como 1000, mucha gente todavía me escribe y me pregunta cosas" De manera similar Frida recuerda:

Cuando empecé a ayudar vi el caos que era entrar (el Multifamiliar), comencé a hacer transmisiones en vivo, yo jamás me imaginé que alguien con cuatrocientos amigos fuera a tener una difusión tan grande al grado que mis compañeros de la escuela, la oficina, personas que viven lejos me decían que era un orgullo ser como la hormiga atómica, entonces comencé a trazar caminos para que llegara la ayuda [...] Me dedico a promover los negocios que están alrededor del Multifamiliar Tlalpan, ya iban a cerrar el de la carnicería, la verdulería y la señora de las quesadillas, pues están junto la zona cero, se tiene que reactivar la economía así que voy saco una foto la subo al face, o hago un Facebook Live.

Por último, el tercer uso estaba vinculado con un elemento clave en la cultura mexicana, disminuir la corrupción y verificar las noticias, por ejemplo, la ciudadanía desconfiaba de la capacidad de respuesta del gobierno. Es muy claro en el testimonio de Jocelyn:

Al segundo día tenía ganas de hacer algo y mi novio me dijo, que fuera al estadio, se necesita gente para verificar las noticias falsas, se envía a la gente a cubrir derrumbes y no es cierto, estuvimos un día en el estadio y después montamos en la cocina de mi novio un centro de información, para verificar noticias y que se necesitaba de medicamentos, alimentos y materia, y así creamos la página de voluntarios UNAM [...] yo nunca había recibido tantas llamadas de gente desconocida en mi vida y además haber hecho amistad con otras personas que nunca lo haría en otras circunstancias.

Por lo tanto, Internet ha constituido un lugar de la misma manera que los lugares físicos mencionados anteriormente. Este lugar no está desconectado de los lugares físicos; sino que es otra dimensión de ellos. Internet ha producido lugareños, por ejemplo, a través de la circulación de los selfies de los voluntarios. Ha ayudado a 
organizar el trabajo en un ritmo más cotidiano y es el principal lugar de reproducción de la memoria de los lugares.

\section{Conclusión: ¿Cómo caracterizar la generación 19S?}

“¿Cuánto dura un instante? Lo suficiente para cambiar una vida. Es lo que podrían decir millones de mexicanos de la 13:44:40 horas del martes 19 de septiembre. Un instante infinito que nos recuerda lo vulnerables que alguna vez fuimos y aún somos." 36

En este proyecto se analizaron los lugares más significativos para los voluntarios en la Ciudad de México tras el sismo del 19 de septiembre de 2017. Nos preguntamos ¿Cómo el salir a apoyar, produjo jóvenes como sujetos de acción? Sobre todo, a medida que su labor de apoyo se organizó desde la espontaneidad en los minutos posteriores al sismo hasta la formación de micro-organizaciones en lugares específicos. Es decir, los jóvenes se vincularon con otros actores sociales para resolver las problemáticas que consideraban urgentes, pero con sus pares generaron vínculos de amistad a partir de sentirse identificados con las emociones que les producían la corrupción, la falta de apoyo del gobierno y sobre todo la muestra de solidaridad entre ellos. Cuando ellos representaban en el mapa sus motivos, desplazamientos era volver a evocar las emociones y valores, pero también el significado del lugar en sus vidas y como esto los marcaba a futuro.

Por ello es relevante, preguntarse ¿cómo se estabilizaron estos lugares para que ya existan en la memoria experiencial de los jóvenes que lo construyeron, y en la memoria colectiva de los habitantes en la producción de la historia del sismo? La visualización de esta memoria permitió desarrollar e intercambiar un lenguaje cartográfico adaptado a la emergencia urbana y sus huellas, pero que de manera tradicional no hubiera sido posible, por ello el valor de la cartografía narrativa, no solo hay que considerarla como medio de visualización, sino como una manera distinta de producir datos cualitativos y espaciales que dotan de una experiencia al lugar significativa para los sujetos.

Se analizó desde una perspectiva subjetiva y experiencial el proceso de construcción de los jóvenes como sujetos de acción a través del apoyo brindado posterior al sismo. Los jóvenes que salieron a las calles reconstruyeron lugares, tanto en sus significados y afectos como en su aspecto estético.

¿Por qué se decide ser voluntario?, ¿cuáles son los efectos emotivos involucrados en su participación? Partiendo de la geografía afectiva, analizamos como la labor de los jóvenes tras el sismo produjo lugares afectivos. Esos lugares generaron empoderamiento y agencia porque el lugar se construye al mismo tiempo que construye lugareños. Son una forma emergente y constructiva de actuar políticamente.

Los lugares producen sujetos, potencia e invención. Permiten mucho más que solo reaccionar frente al Estado. Construir un lugar significa fabricar una ciudad diferente de manera prefigurativa, proactiva. La Generac19n construyó nuevos luga-

36 Aragón, 2018, p. 157 
res afectivos y modos de vida urbana que ponen en relieve nuevas formas de hacer política, fortaleció formas de participación civil y de organización popular que, aunque la perspectiva aún es cercana, permitirá analizar las implicaciones de aquello que puede desarrollarse a un futuro cercano a partir de lo que ocurrió después del 19 de septiembre 2017.

Con la cartografía narrativa y el análisis de las emociones de los participantes en lugares específicos, vemos en que las respuestas de los voluntarios de 2017 tuvieron diferencias importantes respecto a las de 1985, sobre todo en lo relacionado con lo gubernamental: en las calles la diferenciación entre población civil y gobernantes fue clara al momento de las primeras acciones en las calles, ya que mientras el aparato gubernamental tardó en trabajar en las calles, los voluntarios ya tenían claro al menos en lo inmediato, aquello que era necesario hacer.

La Generac19n a través del uso de las herramientas con las que cuentan, iniciaron un proceso de reconstrucción de la ciudad no únicamente física, si no también simbólica y afectiva, fortaleciendo la visión de que la forma en que en la actualidad en el ámbito urbano se hace lo político, ya no es exclusivamente al momento de un proceso electoral o marchando en la calle en reacción a una acción gubernamental como muchas veces era pensada, ahora en palabras de Marco, un participante a la investigación:

La redimensión de la escala politica que generalmente limitamos lo político al sistema partidista, pareciera que este tipo de situaciones de emergencia lo que hacen es que se pueda hacer politica a escala pequeña; organizándote con tu barrio, con tus amigos, con tus compañeros del trabajo te da una forma diferente de trabajo, qué sí puedes y qué no puedes hacer sin depender de otro aparato de representación.

La Generación 19S construyo lugares afectivos que están cambiando la ciudad, sus vidas y el imaginario político. La cartografía afectiva revelo que el enojo o frustración tiene sus orígenes en la desigual actuación entre las juventudes y los elementos de la policía o cuerpos del ejército. La cartografía afectiva no es solamente una herramienta metodológica, es un proceso de reflexión crítica. Como bien lo dice Askins, "entender el mundo racionalmente es solamente una etapa hacia la justicia sustentable: también tenemos que incluir alegría y compasión, odio y envidio dentro de esas ideas y libros, discursos y seminarios." ${ }^{\prime 3}$

\section{Bibliografía:}

ABRAMOWSKI, Ana y Santiago CANEVARO (eds.). Pensar los afectos. Aproximaciones desde las ciencias sociales y las humanidades. Sarmiento: Ediciones UNGS. 2017.

ABREGO, Victor Hugo. Jóvenes en el \#19S. Usos críticos de la Internet en tiempos de crisis. Análisis Plural. Segundo semestre de 2017, ITESO, p. 199-216.

ALLIER MONTAÑO, Eugenia. Memorias imbricadas: terremotos en México, 1985 y 2017. Revista Mexicana de Sociología, 2018. 80 (1): 9-40.

37 Askins, 2019, p. 108 
ARAGÓN, Eduardo. Sismos de septiembre reabren una herida sin sanar. Análisis Plural, 2018, Segundo semestre 2017, ITESO, p.157-169.

ARISTEGUINOTICIAS.COM (2017). El sismo y la doctrina del shock. Aguiar, José Carlos G. [En línea] https://aristeguinoticias.com/2809/mexico/el-sismo-y-ladoctrina-del-shock/ [Consultado 10/11/2018]

ASKINS, Kye. Emotions. Keywords in Radical Geography: Antipode at 50. Oxford, John Wiley \& Sons Ltd. 2019.

AZÓCAR, Pablo. Un análisis epistemológico desde la cartografía postmoderna y su relación con la segunda filosofía de Wittgenstein. Cinta moebio. 59: 129-142. 2017.

BOUDREAU, Julie-Anne. Global Urban Politics: Informalization of the State. Cambridge: Polity Press. 2017.

BURDETT, Ricky. y SUDJIC, Deyan (eds.). Living in the endless city. London: Phaidon. 2010.

CAMARENA LUHRS, Margarita y SALGADO SURYA, Mariana. Cuerpos/emociones de emergencia ante los sismos de México, 2017. Revista Latinoamericana de Estudios sobre Cuerpos, Emociones y Sociedad. 2017, No. 25, Año 9: 34-45.

CASTILLO BERTHIER, Héctor. Temas de coyuntura. Jóvenes, terremotos y cambio social. Revista Mexicana de Sociología. 2018, 80(1): 233-239.

CENTRO DE INSTRUMENTACIÓN Y REGISTRO SÍSMICO (2017): [En línea] http:// Www.cires.org.mx/1985_es.php [Consultado 20/5/2019]

DEPETRIS CHAUVIN, Irene y Natalia TACCETTA. Giro afectivo y artes visuales. Una aproximación interdisciplinaria sobre América Latina. Imagofagia. 2017. 16: 357-369.

ESCOBAR, Arturo y PEDROSA, Alvaro (eds.). Pacifico: ¿desarrollo o diversidad? Estado, capital y movimientos sociales en el Pacifico colombiano. Bogotá: Cerec. 1996.

EL FINANCIERO (2017): [En línea] https://www.elfinanciero.com.mx/sismo-1985/ terremoto-destruyo-del-pib-del-pais [Consultado 20/5/2019]

EXCÉLSIOR. (2018) [En línea] https://www.excelsior.com.mx/ comunidad/2015/09/17/1046211

[Consultado 20/5/2019]

GONZÁLEZ ASCENCIO, Gerardo. La crisis permanente del Estado mexicano vista a la luz de los sismos recientes del 19/S y sus principales consecuencias en la Ciudad de México. Alegatos. 2018, 98 (enero/abril). 171-180.

HARLEY, J. B. The New Nature of Maps: Essays in the History of Cartography. Baltimore, Johns Hopkins University Press. 2001.

KANDINSKY, Wassily. Sobre lo Espiritual en el Arte. México: Colofon.

LÓPEZ LEVI, Liliana y VALVERDE VALVERDE, Carmen. El desastre en la Ciudad de México: ¿Neoliberalismo o terremotos? Topofilia, Revista de Arquitectura, Urbanismo y Territorios Instituto de Ciencias Sociales y Humanidades "Alfonso Vélez Pliego" BUAP 2018, Año XI, No. 16 abril - septiembre. 
MELLA POLANCO, Marcelo. Efectos sociales del terremoto en Chile y gestión política de la reconstrucción durante el gobierno de Sebastián Piñera (20102011 ). Revista Enfoques. 2012, 10(16): 19-46.

MONSIVÁIS, Carlos. Entrada libre. Crónicas de la sociedad que se organiza. México: Biblioteca Era. 1987.

NOLD, Christian (ed.). Emotional Cartography. Creative Commons: www.emotionalcartography.net. 2009.

ORTEGA VALADEZ, Ernesto. Reflexiones sobre los efectos del sismo en la organización vecinal. Estudios Demográficos y Urbanos. 1987, 2(1). Enero-Abril 1987: 141-147.

ORTIZ GUITART, Anna. Cuerpos, emociones y lugar: Aproximaciones teóricas y metodológicas desde la geografía. Geographicalia. 2012. 62: 115-131.

PORTAL BBC (2018): [En línea] https://www.bbc.com/mundo/ noticias/2015/09/150917_mexico_sismo_antes_despues_fotos_an

[Consultado 20/5/2019]

PERAN, Martí. Maneras de hacer mapas. Revista Arquis. 2013, 2(4): 105-122.

SALGADO ANDRADE, Eva. Del \#SimulacroCDMX al \#MexicoNosNecesita: 19S en Twitter. Revista Mexicana de Sociología. 2018, 80(1): 121-147.

SANSAO-FONTES, Adriana y Joy TILL. Cartografía afectiva de Rio de Janeiro: Intervenciones temporales y urbanismo táctico para la reconquiste del espacio público. Placemaking LatinoAmérica. La reconquista del espacio público. ler Encuentro de Innovación Urbana Ciudadana Placemaking. Valparaíso, noviembre 2017: 247-257.

SCHTEINGART, Martha y LEZAMA, José Luis. Crisis urbana y respuestas populares. El impacto social del sismo en la Ciudad de México. Estudios Latinoamericanos. 1986, 1(1): 19-27.

SECRETARIA DE CULTURA DE LA CIUDAD DE MÉXICO. ¿Y cómo viviste el temblor? Antología de testimonios. Gobierno de la Ciudad de México. 2018.

STREET, Susan. Movimientos sociales y el análisis del cambio sociopolítico en México. Revista Mexicana de Sociología. 1991, 53(2). Abril- Junio 1991: 141-158.

THRIFT, Nigel. Intensities of feeling: towards a spatial politics of affect" Geografiska Annaler 86(1): 57-78. 2004.

VELÁZQUEZ GUTIÉRREZ, Margarita. Desastres sociales: sismos, reconstrucción e igualdad de género. Revista Mexicana de Sociología. 2018, 80(1): 149-158.

VERGARA FIGUEROA, Abilio. Etnografía de los lugares. Una guia antropológica para estudiar su concreta complejidad. Segunda edición. Ciudad de México: Ediciones Navarra. 2015.

WIENER CASTILLO, Gabriela. Representación espacial y bienestar social. Colonia La Planta, Iztapalapa a un mes del sismo. Academia XXI. 2017, Segunda Época. 8(16). Diciembre 2017: 93-107. 
ZARYCKI, T. On the pragmatic approach to map analysis. Remarks on the basis of MacEachren's approach to map semiotics, pp. 64-70. In: A. Wolodtschenko. The selected problems of theoretical cartography. Dresden: Proceedings of the Commission on Theoretical Cartography 2000. International Cartographic Association. 2001.

(C) Copyright: Julie Boudreau et al., 2020

(c) Copyright: Scripta Nova, 2020.

Ficha bibliográfica:

BOUDREAU, Julie; CASTRO, Carlos; MEJÍA, Evelyn; ROMERO, Tonalli. Generación 19S. Cartografía afectiva del sismo del 19 de septiembre 2017 en México. Scripta Nova. Revista Electrónica de Geografía y Ciencias Sociales. Barcelona: Universidad de Barcelona, I de Mayo de 2020, vol. XXIV, nº 637. [ISSN: 1138-9788] 